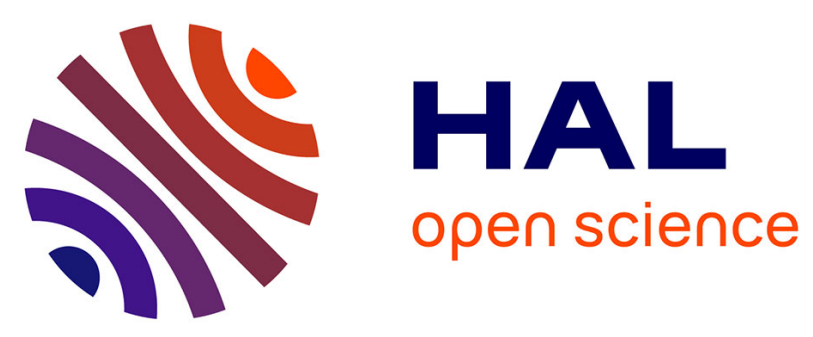

\title{
Exploiting Light Interferences to Generate Micrometer-High Superstructures from Monomeric Azo Materials with Extensive Orientational Mobility
}

Florent Rodriguez, Joachim Jelken, Nicolas Delpouve, Adèle Laurent, Bertrand Garnier, Jean-luc Duvail, François Lagugné-labarthet, Eléna Ishow

\section{To cite this version:}

Florent Rodriguez, Joachim Jelken, Nicolas Delpouve, Adèle Laurent, Bertrand Garnier, et al.. Exploiting Light Interferences to Generate Micrometer-High Superstructures from Monomeric Azo Materials with Extensive Orientational Mobility. Advanced Optical Materials, 2021, pp.2100525. 10.1002/adom.202100525 . hal-03266377

\section{HAL Id: hal-03266377 https://hal.science/hal-03266377}

Submitted on 26 Jul 2021

HAL is a multi-disciplinary open access archive for the deposit and dissemination of scientific research documents, whether they are published or not. The documents may come from teaching and research institutions in France or abroad, or from public or private research centers.
L'archive ouverte pluridisciplinaire HAL, est destinée au dépôt et à la diffusion de documents scientifiques de niveau recherche, publiés ou non, émanant des établissements d'enseignement et de recherche français ou étrangers, des laboratoires publics ou privés. 


\title{
Exploiting Light Interferences to Generate Micrometer-High Superstructures from Monomeric Azo Materials with Extensive Orientational Mobility
}

\author{
Florent Rodriguez, Joachim Jelken, Nicolas Delpouve, Adèle Laurent, Bertrand Garnier, \\ Jean-Luc Duvail, François Lagugné-Labarthet, and Eléna Ishow*
}

Photochromic azo materials have stirred considerable interest for their ability to mechanically respond to polarized light through large photo-induced migration and orientation processes. In order to apprehend the microscopic dynamics behind the extensive mass transport occurring under interferential illumination, two azo compounds differing by their propen-sity to form hydrogen bonds are synthesized and processed as nondoped glassy thin films. Interferential irradiation using polarization and intensity patterns reveals fully distinct responses. Regular nanometer-high surface relief gratings transform into micrometer superstructures with an ampli-tude ten times higher than the initial film thickness when using the latter polarization. Systematic comparisons between the azo materials in terms of thermal properties, photochromism in solution and in the solid state, and photomigration are carried out. The progressive formation of super-structures is ascribed to two successive processes. The first one relates to fast photoinduced migration due to the impinging structured light, and the second one is promoted by slower thermally activated "zig-zag"-like diffu-sion and Z-E thermal relaxation, which in turn requests high orientational mobility of the azo compounds and causes large nanomechanical changes. Such studies should provide novel structural guidelines in terms of material fluidity to rapidly achieve highly structured and rewritable materials at low light irradiance.

\section{Introduction}

Azo compounds have boosted fascinating developments in the field of photo-actuators owing to their ability to undergo large and reversible geometrical changes upon photon absorption. ${ }^{[1]}$ Numerous azo polymer materials, ${ }^{[2]}$ and especially liquid crystal ones, ${ }^{[3]}$ have been designed to induce massive motions under polar-ized light in controlled directions, taking advantage of the mesogenic character of the rod-like azo chromophores ${ }^{[4]}$ and their polarizationdependent photo-chromic response. ${ }^{[5]}$ In this way, coop-erative interactions produce considerable deformations that found applications in solar energy storage, ${ }^{[6]}$ gene photoregula-tion, ${ }^{[7]}$ and surface patterning for fabri-cating photonic devices, ${ }^{[8]}$ or triggering cell adhesion, ${ }^{[9]}$ to cite only a few. The complex structure of such liquid crystal polymers and the degree of structural vari-ability issued from noncontrolled radical polymerization prompted several groups to propose monomeric materials, ${ }^{[10]}$ made exclusively of small photochromic

F. Rodriguez, Dr. A. Laurent, Prof. E. Ishow

Université de Nantes

CEISAM-UMR CNRS 6230

2 rue de la Houssinière, Nantes 44 322, France

E-mail: elena.ishow@univ-nantes.fr

Dr. J. Jelken, Prof. F. Lagugné-Labarthet

Department of Chemistry

University of Western Ontario (Western University)

1151, Richmond St., London, Ontario N6A 5B7, Canada

Dr. N. Delpouve

Normandie Université

UNIROUEN Normandie

INSA Rouen

CNRS

Groupe de Physique des Matériaux

Rouen 76000, France
Dr. B. Garnier

Université de Nantes

LTeN-UMR CNRS 6607, Polytech Nantes, rue Christian Pauc

Nantes 44306, France

Prof. J.-L. Duvail

Institut des Matériaux Jean Rouxel

Université de Nantes

CNRS

IMN

Nantes F-44000, France 
molecules, which simplifies the fabrication procedure and ensures size unicity and reproducibility thereof. In the search for cooperativity in the solid state, ${ }^{[1]}$ efforts to introduce the concepts of supramolecular chemistry led to the fabrication of azo molecules amenable to noncovalent interactions through ion pairing, ${ }^{[12]}$ hydrogen bonds, ${ }^{[13]}$ or halogen bonds. ${ }^{[14]}$ Despite the low payload of azo entities, such materials revealed remarkable photoinduced mass transfer when subjected to interferential light, which afforded the formation of surface relief gratings following the periodic optical patterns of the impinging light as a result of an overall photomigration of matter. ${ }^{[15]}$ In this case, photoisomerization and thermal reorientation of the azo units occurred first and were followed by the subsequent motion of the interacting partners, which led to amplified and cooperative displacement. ${ }^{[16]}$ Nevertheless, since the azo compounds needed to drive their neighboring chemical entities, azo migration was partly hampered, slowing down the writing dynamics. ${ }^{[17]}$ Moreover, host-guest or multi-component systems were mostly implied in the reported studies, which conducted to low amounts of incorporated azo units, less than a few percent, and limited deep structuration of the illuminated thin films. Working with monocomposite materials, comprising only the photoactive molecules, would thus not only reduce the risks of segregation for gaining time stability but also allow for better understanding of the microscopic structural organization and the underlying migration phenomena. Fine balance between significant intermolecular interactions, especially hydrogen bonding, and photoisomerization efficiency in the solid state thus needs to be found. Acidic units, like phosphonic and carboxylic ones, could appear among the most attractive promoters of intermolecular $\mathrm{H}$ bonds with less stringent orientation criteria compared to amide or urea units ${ }^{[18]}$ implying adequate mutual organization. Recent studies revealed that the incorporation of phosphonic acid units and especially bisphosphonic ones exerted stiff interactions that fully prohibited photoisomerization in the solid state, ${ }^{[19]}$ and even provoked intermolecular proton transfer until modifying the absorption properties of the azo compounds. ${ }^{[20]}$ Curiously, azo molecules comprising carboxylic acid units have rarely been considered as potential photoactuators, presumably due to their tendency to crystallize in the solid state, impairing efficient photomigration, whereas they have been involved in the construction of photoswitchable metal organic frameworks for light harvesting applications. ${ }^{[21]}$ In the current study, we provide new guidelines in the design of azo derivatives amenable to undergo extensive collective photoinduced migration based on the comparative photophysical, photochromic, thermal, and electronic properties between azo compounds comprising a carboxylic acid unit and their ester analogs. Photoreaction in solution and solid state, completed by calorimetric analyses, gives access to a multiscale description from statistical ensembles of solvated molecules to monomeric glasses, and shines light on the influence of intermolecular interactions for performing migration processes. Finally, for the first time to our knowledge, clear demonstration of the occurrence of distinct mechanisms in terms of mass transport kinetics and direction is evidenced between polarization- and intensity-photodriven processes, giving rise to huge structural deformations with respect to the initial thickness. Systematic structural and dynamic comparisons between the compounds offer novel elements to rationalize the optical effects underlying the formation of micrometer-high structures, thereby providing attractive guidelines to design photoactivatable materials and photofabricate organized microstructures with no additional promoter.

\section{Experimental Section}

\subsection{Synthesis and Thin Film Fabrication}

\subsubsection{General Procedures}

Bis (4'-tert-butylbiphenyl-4-yl)-4-aminophenylamine ${ }^{[22]}$ and 4-nitrosobenzoate ${ }^{[23]}$ were synthesized according to literature procedures. All reagents and solvents were purchased from commercial sources and used without further purification. UVvisible absorption spectra were acquired using a Cary 5E UVVIS-NIR (Agilent) spectrometer. ${ }^{1} \mathrm{H}$ and ${ }^{13} \mathrm{C}$ NMR spectra were done with an AVANCE $300 \mathrm{MHz}$ Bruker spectrometer at $298 \mathrm{~K}$. High-resolution mass (HR-MS) spectra were obtained either by electrospray ionization coupled with high resolution ion trap orbitrap (LTQ-Orbitrap, Thermo Fisher Scientific).

Synthesis of 4-[4'[bis(4'-tertbutylbiphenyl-4-yl)amino]phenylazo] benzoate $\left(\mathrm{azoCO}_{2} \mathrm{Me}\right)$ (adapted procedure from previously reported synthesis $\left.{ }^{[24]}\right)$ : To a solution of bis $\left(4^{\prime}\right.$-tert-butylbiphenyl4-yl)-4-aminophenylamine (1.00 g, $1.91 \mathrm{mmol})$ in acetic acid $(35 \mathrm{~mL})$ in a round-bottomed flask equipped with a magnetic stirrer was added 4-nitrosobenzoate $(0.30 \mathrm{~g}, 1.84 \mathrm{mmol})$ at ambient temperature. Once the addition was complete, the solution was stirred for $48 \mathrm{~h}$ in the dark at ambient temperature. The black-red solid was filtered off, and thoroughly washed with acetonitrile $(10 \mathrm{~mL})$ to yield $\mathbf{a z o C O} \mathbf{C O}_{2} \mathrm{Me}$ as a dark red powder (1.07 g, $1.59 \mathrm{mmol}, 87 \%) .{ }^{1} \mathrm{H}$ NMR $(300 \mathrm{MHz}$, $\left.\mathrm{CDCl}_{3}, 298 \mathrm{~K}\right) \delta: 8.17\left(\mathrm{~d},{ }^{3} \mathrm{~J}=8.7 \mathrm{~Hz}, 2 \mathrm{H}\right), 7.91\left(\mathrm{~d},{ }^{3} \mathrm{~J}=8.9 \mathrm{~Hz}\right.$, $2 \mathrm{H}), 7.88\left(\mathrm{~d},{ }^{3} \mathrm{~J}=9.5 \mathrm{~Hz}, 2 \mathrm{H}\right), 7.57\left(\mathrm{~d},{ }^{3} \mathrm{~J}=8.6 \mathrm{~Hz}, 4 \mathrm{H}\right), 7.54(\mathrm{~d}$, $\left.{ }^{3} \mathrm{~J}=8.6 \mathrm{~Hz}, 4 \mathrm{H}\right), 7.47\left(\mathrm{~d},{ }^{3} \mathrm{~J}=8.6 \mathrm{~Hz}, 4 \mathrm{H}\right), 7.27\left(\mathrm{~d},{ }^{3} \mathrm{~J}=9.0 \mathrm{~Hz}\right.$, $4 \mathrm{H}), 7.21(\mathrm{~d}, 3 \mathrm{~J}=9.0 \mathrm{~Hz}, 2 \mathrm{H}), 3.95$ (s, 3H), 1.37 (s, 18H) ppm. ${ }^{13} \mathrm{C}$ NMR (75 MHz, $\left.\mathrm{CDCl}_{3}, 298 \mathrm{~K}\right) \delta: 166.7,155.5,151.1,150.2$, $147.1,145.5,137.5,137.1,130.9,130.6,128.1,126.5,125.8,124.8$, 122.3, 121.5, 53.4, 52.3, 34.6, 31.4 ppm. HRMS (ESI+) $m / z[\mathrm{M}]^{+}$: calcd for $\mathrm{C}_{46} \mathrm{H}_{45} \mathrm{~N}_{3} \mathrm{O}_{2}$, 671.3512; found, 671.3518. UV-vis (tetrahydrofuran (THF)), $\lambda_{\max }(\mathrm{nm})\left[\varepsilon_{\max }\left(\mathrm{L} \mathrm{mol}^{-1} \mathrm{~cm}^{-1}\right]\right.$ of $E$ isomer: $328\left[3.50 \times 10^{4}\right], 465\left[3.20 \times 10^{4}\right]$. UV-vis $\left(\mathrm{CHCl}_{3}\right), \lambda_{\max }(\mathrm{nm})$ $\left[\varepsilon_{\max }\left(\mathrm{L} \mathrm{mol}^{-1} \mathrm{~cm}^{-1}\right]\right.$ of $E$ isomer: $330\left[3.42 \times 10^{4}\right], 474\left[2.89 \times 10^{4}\right]$. Synthesis of 4-[4'[bis(4'-terbutylbiphenyl-4-yl)amino]phenylazo] benzoic acid $\left(\operatorname{azoCO}_{2} \mathrm{H}\right)$ : Compound $\operatorname{azoCO}_{2} \mathrm{Me}(0.36 \mathrm{mmol}$, $0.240 \mathrm{~g})$ was dissolved in 2-methoxyethanol $(15 \mathrm{~mL})$ in a roundbottomed flask equipped with a magnetic stirrer. Aqueous 3 м KOH solution was added (102 mmol, $5 \mathrm{~mL})$. The mixture was subsequently heated at $120^{\circ} \mathrm{C}$ for $18 \mathrm{~h}$. The solution was allowed to cool down to room temperature before adding dropwise a solution of hydrochloric acid $1 \mathrm{~m}$ until reached a neutral $\mathrm{pH}$. The dark precipitate that formed was filtered off on a glass frit and washed with water. The solid was redissolved in $\mathrm{CH}_{2} \mathrm{Cl}_{2}$, and the solution dried over anhydrous $\mathrm{Na}_{2} \mathrm{SO}_{4}$ before solvent evaporation to dryness to yield $\mathbf{a z o C O}_{2} \mathrm{H}$ as a pure brown powder $(0.170 \mathrm{~g}, 0.26 \mathrm{mmol}, 73 \%) .{ }^{1} \mathrm{H}$ NMR $(300 \mathrm{MHz}$, $\left.\mathrm{CDCl}_{3}, 298 \mathrm{~K}\right) \delta: 8.23\left(\mathrm{~d},{ }^{3} \mathrm{~J}=8.7 \mathrm{~Hz}, 2 \mathrm{H}\right), 7.94\left(\mathrm{~d},{ }^{3} \mathrm{~J}=8.7 \mathrm{~Hz}\right.$, 
2H), $7.89\left(\mathrm{~d},{ }^{3} J=9.0 \mathrm{~Hz}, 2 \mathrm{H}\right), 7.57$ (d, $\left.{ }^{3} J=8.6 \mathrm{~Hz}, 4 \mathrm{H}\right), 7.56$ (d, $\left.{ }^{3} J=8.6 \mathrm{~Hz}, 4 \mathrm{H}\right), 7.48\left(\mathrm{~d},{ }^{3} J=8.6 \mathrm{~Hz}, 4 \mathrm{H}\right), 7.27\left(\mathrm{~d},{ }^{3} J=9.0 \mathrm{~Hz}\right.$, $2 \mathrm{H}), 7.22\left(\mathrm{~d},{ }^{3} J=9.0 \mathrm{~Hz}, 2 \mathrm{H}\right), 5.30(\mathrm{~s}, 1 \mathrm{H}), 1.37$ (s, 18H) ppm. ${ }^{13} \mathrm{C}$ NMR (75 MHz, $\left.\mathrm{CDCl}_{3}, 298 \mathrm{~K}\right) \delta: 170.6,156.1,151.2,150.3$, $147.1,145.5,137.5,137.2,131.3,129.9,128.1,126.5,125.9,125.8$, 124.9, 122.4, 121.4, 34.6, 31.4 ppm. HRMS (ESI+) $\mathrm{m} / z \mathrm{M}]^{+}$: calcd for $\mathrm{C}_{45} \mathrm{H}_{43} \mathrm{~N}_{3} \mathrm{O}_{2}$, 657.3355; found, 657.3258. UV-vis (THF), $\lambda_{\text {max }}(\mathrm{nm})\left[\varepsilon_{\max }\left(\mathrm{L} \mathrm{mol}^{-1} \mathrm{~cm}^{-1}\right]\right.$ of $E$ isomer: $327\left[3.82 \times 10^{4}\right], 461$ $\left[3.15 \times 10^{4}\right]$. UV-vis $\left(\mathrm{CHCl}_{3}\right), \lambda_{\max }(\mathrm{nm})\left[\varepsilon_{\max }\left(\mathrm{L} \mathrm{mol}^{-1} \mathrm{~cm}^{-1}\right]\right.$ of $E$ isomer: $330\left[3.34 \times 10^{4}\right], 471\left[2.85 \times 10^{4}\right]$.

Preparation of Thin Films: Solutions of azo compound were prepared at a concentration of $2 \mathrm{wt} \%$ in spectroscopic grade $\mathrm{CHCl}_{3}$ and sonicated for $10 \mathrm{~min}$. Glass slides $\left(2 \times 2 \mathrm{~cm}^{2}\right)$, used as a substrate, were cleaned by ultra-sound in a $2 \%$ alkaline solution for $30 \mathrm{~min}$ (Hellmanex), and rinsed with Millipore water and ethanol before drying under $\mathrm{N}_{2}$ atmosphere. The solutions were filtered using $0.45 \mu \mathrm{m}$ PTFE membrane filters. They were deposited on the glass substrate by spin-coating (1500 rpm rotation speed, $500 \mathrm{rpm} \mathrm{s}^{-1}, 90 \mathrm{~s}$ rotation time) to yield uniform and amorphous films with a 200-230 nm thickness. All films were dried at room temperature to remove the solvent. Thin film thickness was measured by atomic force microscope (AFM) after scratching the surface with a scalpel knife.

\subsection{Thermal Analyses and IR Spectroscopy}

\subsubsection{Thermal Analyses}

Glass transition temperature ranges of the investigated systems were obtained from classical differential scanning calorimetry (DSC) performed at $10 \mathrm{~K} \mathrm{~min}^{-1}$, under a nitrogen flow of $50 \mathrm{~mL} \mathrm{~min}{ }^{-1}$, using a TA Q2000 apparatus. The calibration included an empty run to establish the baseline, the cell resistance, and capacitance using the Tzero procedure, and a DSC run of indium at $10 \mathrm{~K} \mathrm{~min}^{-1}$ for both temperature and energy. To optimize the sample/sensor contact, the powdered samples in the DSC pan were slowly led to the liquid state on a Kofler bench, and then quenched to form glassy films that were found stable over months.

\subsubsection{IR Spectroscopy}

IR spectroscopy measurements were performed using a FTIR Bruker Tensor 27 spectrometer and an attenuated total reflectance accessory equipped with a germanium crystal.

\subsection{Photochromism Investigations, Holography Experiments, and Mechanical, Optical, and Photothermal Measurements}

\subsubsection{Photophysics and Photochromic Reactions}

Solutions of azo compounds were prepared at a concentration of $1.7 \times 10^{-5} \mathrm{~mol} \mathrm{~L}^{-1}$ in $\mathrm{CHCl}_{3}$ and THF and sonicated for $10 \mathrm{~min}$. They were irradiated under vigorous stirring using a $\mathrm{Hg}$-Xe light source, equipped with a quartz fiber and a narrow band bandpass filter (488 nm, full-width at half-maximum $25 \mathrm{~nm}, 7 \mathrm{~mW} \mathrm{~cm}{ }^{-2}$ irradiance) for $60 \mathrm{~s}$. Absorption spectra were recorded after each irradiation step with a Varian Model Cary $5 \mathrm{E}$ spectrophotometer until reaching the stationary state. The above-described thin films were irradiated using the same experimental setups. Overlap between the irradiation spot and the probing beam of the spectrophotometer was ensured using a paper mask. As for back thermal relaxation, solutions and thin films stood overnight in the spectrometer and time absorbance evolution as recorded at five distinct wavelengths for $1000 \mathrm{~min}$ for azo solutions and $1200 \mathrm{~min}$ for azo thin films.

\subsubsection{Holographic Writing}

Surface relief gratings were written and erased using an interferometer optical setup, previously described in literature and involving an ion Ar laser for writing and a low-power $\mathrm{He}-\mathrm{Ne}$ laser for probing $\left(1.9 \mathrm{~mW}\right.$ power). ${ }^{[25]}$ Two polarization configurations were used, namely, $+45^{\circ} /-45^{\circ}$ and $\mathrm{p} / \mathrm{p}$ to provide periodic polarization and intensity patterns, respectively. Diffraction efficiency $\eta$ was calculated as the ratio of the first-order diffracted intensity $I_{ \pm 1}$ to the initial incident intensity $I_{0}$ of the He-Ne probe laser beam.

\subsubsection{Atomic Force Microscopy (AFM)}

Topographic AFM imaging was performed in a noncontact mode using a NanoWizard 4 atomic force microscope (JPK, Germany) equipped with an $x-y$ closed-loop control system.

\subsubsection{Quantitative Nanomechanical Mapping (QNM)}

QNM was performed using a Bruker BioScope Catalyst AFM positioned over an inverted optical microscope (Zeiss Axiovert 200M). The AFM was working in the PeakForce QNM mode which mapped, beside the topography, nanomechanical properties including Young's modulus, adhesion, dissipation, and deformation with high spatial resolution. The scan speed of AFM was set to $0.125 \mathrm{~Hz}$ with a scan area of $20 \mu \mathrm{m} \times 20 \mu \mathrm{m}$ and a resolution of 512 pixel $\times 512$ pixel. Commercial tips (Nanoworld Pointprobe NCLR) with a resonance frequency of $190 \mathrm{kHz}$, a spring constant of $30 \mathrm{~N} \mathrm{~m}^{-1}$ (measured by thermal tune), and a tip radius of $8 \mathrm{~nm}$ were used for the measurements. The sensitivity of the system was measured by performing a force versus distance curve on a stiff material (no deformation, clean Si waver). The PeakForce frequency was set to 0.5 and $1 \mathrm{kHz}$. The Young's modulus and adhesion force were obtained from the withdraw curve by applying the DMT (Derjaguin-MullerToporov) model.

\subsubsection{Optical Imaging}

The optical microscope measurements were carried out using an upright microscope (Zeiss Axioskop) at $20 \times$ magnification. 


\subsubsection{Photothermal Imaging}

IR thermal imaging was performed using the photothermal camera FLIR XC7500 InSb with a $50 \mathrm{~mm}$ objective $(30 \mu \mathrm{m}$ spatial resolution, $20 \mathrm{mK}$ thermal resolution, $3 \mathrm{~ms}$ sampling time) that mapped the temperature evolution in a front face configuration with respect to the side of the illuminated azo thin film.

\subsection{Computational Studies}

Desity-functional theory (DFT) and time-dependent DFT (TDDFT) calculations were performed in THF solution. The structures were optimized at the PCM-CAM-B3LYP/6-31+G(d) level of theory and no imaginary frequencies were observed ensuring that molecules were in their true minima of the potential energy surfaces. Vertical excitation energies and electron difference plots (contour threshold of 0.0008 a.u.) were obtained at the PCM-TD-CAM-B3LYP/6-311+G(2d,p) level using the corrected linear response scheme $(\mathrm{cLR})^{[26]}$ as such a formalism was optimal for push-pull dyes. ${ }^{[27]}$ All calculations were carried out with the Gaussian16 program ${ }^{[28]}$ tightening both self-consistent field $\left(10^{-10}\right.$ a.u.) and geometry optimization $\left(10^{-5}\right.$ a.u. $)$ convergence.

\section{Results And Discussion}

\subsection{Design Strategy}

The fabrication of photoswitchable monomeric materials with performing mobility properties requires first sufficient free volume to adapt the large photoinduced changes in geometry, and second amorphous properties to avoid scattering light effects by microcrystalline areas. These structural imperatives prompted us to incorporate the bulky and twisted triarylamino group, known to impart thin films with glassy properties and shift to the visible range the dye absorption band, promoting $E-Z$ and $E-Z$ photoisomerization at the same wavelengths (Figure 1). ${ }^{[10 b, 29]}$ In addition, the search for cooperative motions in bulk samples makes rigid backbones more favorable over flexible ones, which limits the number of bond vibrations participating less efficiently to the migration of the ensemble, hence the carboxylic acid unit was directly attached to the azo aromatic rings. In order to evaluate the intermolecular interactions developed between the carboxylic units and their surroundings in solution and thin films, we synthesized an ester photoswitchable analogous, devoid of hydrogen bonds and serving as a model compound. Advantageously, the synthesis of the azo carboxylic acid derivative $\mathbf{a z o C O}_{2} \mathrm{H}$ derived from saponification of the ester analog $\mathbf{a z o C O} \mathrm{CO}_{2} \mathrm{Me}$, simply obtained by reacting methyl 4-nitrosobenzoate with a bulky triarylamine compound.

IR measurements were performed on the dried powder to ensure complete hydrolysis, which otherwise would dramatically impact the photochromic measurements. The carbonyl group of the ester compound $\mathbf{a z o C O}_{2} \mathrm{Me}$ indeed displays an intense stretching band at $1720 \mathrm{~cm}^{-1}$ due to $\pi$-conjugation with the aromatic ring whereas that for $\mathbf{a z o C O}_{2} \mathrm{H}$ resonated at $1682 \mathrm{~cm}^{-1}$, as a result of intermolecular $\mathrm{H}$ bonds, also characterized by a broad and low-energy stretching band of the $\mathrm{O}-\mathrm{H}$ oscillators at around $3000 \mathrm{~cm}^{-1}$ (Figure S1, Supporting Information). Thermal analyses performed by DSC revealed for both compounds azoCO${ }_{2} \mathrm{Me}$ and $\operatorname{azoCO}_{2} \mathrm{H}$ a glass transition temperature valued at 110 and $140{ }^{\circ} \mathrm{C}$, respectively, and no crystalline feature, proving the efficient role of the bulky triarylamino groups to prevent dye aggregation in the solid state (Figure S2, Supporting Information). This difference can easily be interpreted in terms of intermolecular interactions since the promotion of hydrogen bonding increases the glass transition temperature. ${ }^{[30]}$ Therefore, the broader transition and higher temperature found for the acidic derivative are consistent with the presence of intermolecular hydrogen bonds as already noted for the $\mathrm{O}-\mathrm{H}$ stretching band.

\subsection{Influence of Solvent Proticity and Polarizability on Photoreactivity}

In order to gain insight in the molecular interactions between the azo dyes when processed as neat thin films and their ability to photoisomerize, which is pre-requisite for efficient photomigration, we first explored their electronic properties in solution. The influence of four solvents, toluene, THF, chloroform,
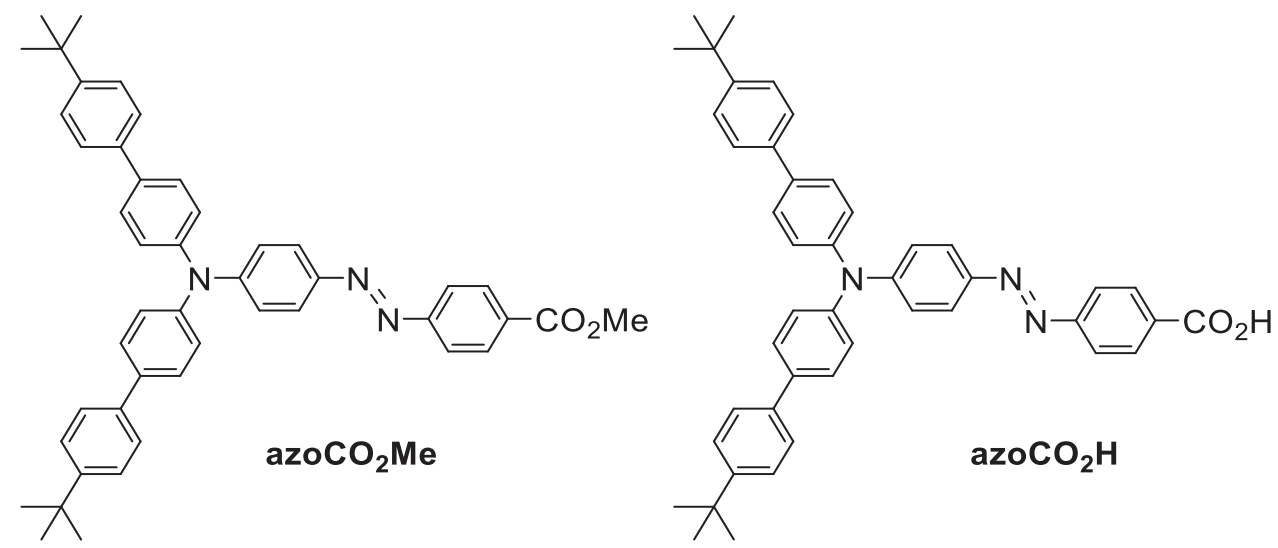

Figure 1. Structure of the glass-forming photoresponsive molecules $\mathrm{azoCO}_{2} \mathrm{Me}$ and $\mathbf{a z o} \mathrm{CO}_{2} \mathrm{H}$. 
Table 1. UV-vis absorption and photochromic properties of $\mathbf{a z o C O}_{2} \mathrm{Me}$ and $\mathbf{a z o C O}{ }_{2} \mathrm{H}$ in various solvents, ranked following increasing hydrogen-bond donating ability.

\begin{tabular}{|c|c|c|c|c|c|c|}
\hline & \multicolumn{2}{|c|}{$\lambda^{\mathrm{UV}}{ }_{\text {max }}, \lambda^{\mathrm{vis}}{ }_{\max }[\mathrm{nm}]$} & \multicolumn{2}{|c|}{$\rho \mathrm{EZ}^{\min }[\%]^{\mathrm{a})}$} & \multicolumn{2}{|c|}{$k_{\mathrm{ZE}}\left[10^{-4} \mathrm{~s}^{-1}\right]^{\mathrm{b})}$} \\
\hline & $\mathrm{azoCO}_{2} \mathrm{Me}$ & $\mathrm{azoCO}_{2} \mathrm{H}$ & $\mathrm{azoCO}_{2} \mathrm{Me}$ & $\mathrm{azoCO}_{2} \mathrm{H}$ & $\mathrm{azoCO}_{2} \mathrm{Me}$ & $\mathrm{azoCO}_{2} \mathrm{H}$ \\
\hline THF & 328,465 & 327,461 & 49 & 49 & 1.2 & 1.2 \\
\hline Toluene & 330,466 & 328,466 & 45 & 45 & 0.9 & 1.5 \\
\hline $\mathrm{CHCl}_{3}$ & 330,474 & 330,471 & 37 & 35 & 2.1 & 1.8 \\
\hline $\mathrm{EtOH}$ & 324,462 & 325,442 & 38 & 37 & 1.4 & 9.5 \\
\hline
\end{tabular}

a) Estimated at the photostationary state, following the rough assumption of nonabsorbing Z-isomers; b) Thermal back relaxation rate constant inferred from mono-exponential fit of the absorbance recovery of the solution in the dark at room temperature (RT).

and ethanol differing in their polarity or H-bonding accepting/ donating properties according to the Kamlet-Taft classification was investigated to apprehend possible molecular interactions in the solid state (Table S1, Supporting Information). The absorption spectra of both compounds display two bands in all solvents (Figure S3, Supporting Information and Table 1).

The first one in the UV range, found around $325-330 \mathrm{~nm}$, was ascribed to charge transfer from the triphenylamino group to the biphenyl arms as inferred from previous TD-DFT calculations. ${ }^{[31]}$ The second one, in the visible range, underwent significant shift in ethanol and $\mathrm{CHCl}_{3}$, endowed with the strongest $\mathrm{H}$-bonding donating behavior among the aprotic or apolar solvents. Such shift $\Delta \pi_{\max }$ is particularly notable for azoCO ${ }_{2} \mathrm{H}$ where $\Delta \lambda_{\max }$ decreased by $-29 \mathrm{~nm}$ against $-12 \mathrm{~nm}$ for $\mathrm{azoCO}_{2} \mathrm{Me}$ when going from chloroform to ethanol, whereas the absorption maximum wavelength was almost constant at around $461-466 \mathrm{~nm}$ for both compounds in THF and toluene solution. This solvent sensitivity agrees with the charge transfer character of the electronic transition in the visible, implying the electron-withdrawing azo unit and the directly connected carboxylic acid or ester function (Figure S4, Supporting Information). It also evidences the mutual interplay between the carbonyl units and the solvent molecules, letting anticipate distinct behaviors between both azo dyes when processed as nondoped thin films. The latter were obtained with a high optical quality from spin-coating a $2 \mathrm{wt} \%$ dye solution and subsequent drying. Interestingly, the absorption maxima for $\mathrm{azoCO}_{2} \mathrm{Me}$ and $\mathbf{a z o C O}_{2} \mathrm{H}$ thin films were found to be significantly distinct at 469 and $474 \mathrm{~nm}$, respectively, which tends to suggest possible differentiated photomigration capabilities in the solid state as a result of intermolecular hydrogen bonds (Figure 2).

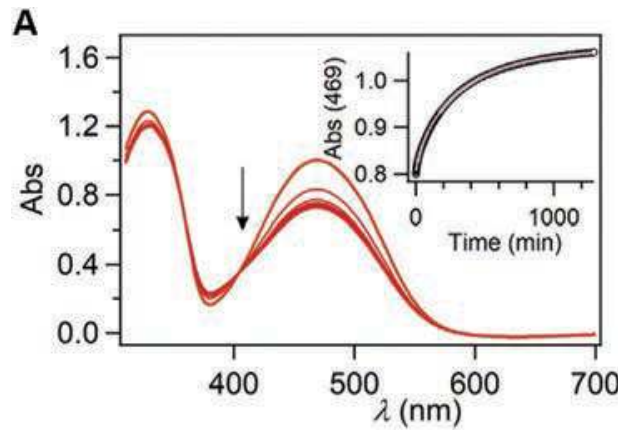

Since all further photomigration experiments were performed using an argon ion laser at $488 \mathrm{~nm}$ close to the azo absorption maximum wavelength, the E-to-Z photoisomerization reaction was investigated using a Hg-Xe lamp equipped with a narrow bandpass filter centered at $488 \mathrm{~nm}$, also matching the thin film absorbance maximum. Phototransformation of azoCO ${ }_{2} \mathrm{Me}$ and $\mathbf{a z o C O}_{2} \mathrm{H}$ from $E$ to $Z$ isomers showed typical features of pseudo-stilbene azo derivatives where the visible band, consisting of overlapping $n \pi^{*}$ and $\pi \pi^{*}$ electronic transitions, ${ }^{[32]}$ significantly decreased without showing additional bands at lower energy as encountered for symmetrical azo compounds (Figure S3, Supporting Information and Table 1). ${ }^{[33]}$

Full reversibility was obtained by leaving the solutions or thin films relax in the dark at ambient temperatures. Interestingly, while the photochromic behavior was found the same in THF or toluene solution for both compounds, slight differences could be noted in chloroform and ethanol solution especially. The estimated minimum photoconversion yield $\rho \mathrm{EZ}^{\mathrm{min}}$ dropped to $35-37 \%$ in H-bond donating solvents contrary to nondonating THF and toluene solvents where larger photoconversion was achieved with $\rho_{\mathrm{EZ}}{ }^{\mathrm{min}}$ values of $45-49 \%$. It is particularly worth noting that $\mathbf{a z o C O}_{2} \mathrm{H}$ underwent accelerated back thermal Z-to-E isomerization whose rate constant $k_{\mathrm{ZE}}$, calculated from a monoexponetial fit, was found one order of magnitude larger in ethanol $\left(k_{\mathrm{ZE}}=9.5 \times 10^{-4} \mathrm{~s}^{-1}\right)$ with respect to those in the other solvents or those for $\mathbf{a z o C O}_{2} \mathrm{Me}$ compound $\left(k_{\mathrm{ZE}}=\right.$ $0.9-2.1 \times 10^{-4} \mathrm{~s}^{-1}$ ) (Table 1). This significant difference, making compound $\operatorname{azoCO}_{2} \mathrm{H}$ relaxing more efficiently in ethanol and chloroform can be interpreted as a result of vibrational coupling with $\mathrm{H}$-donating solvents, decreasing the thermal energy barrier between the photogenerated $Z$ forms and more stable

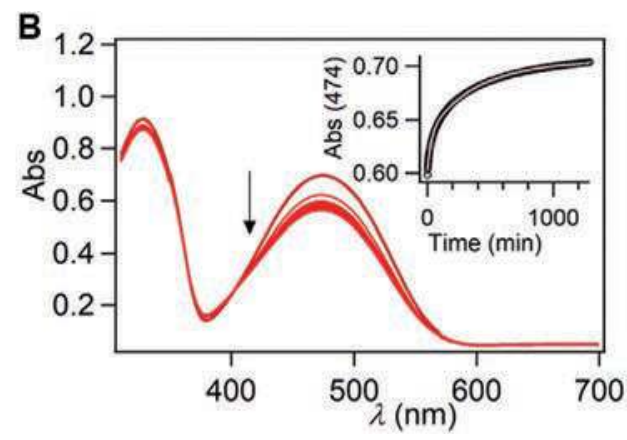

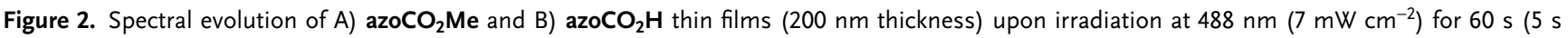
time interval). Black arrows indicate the absorption change of films until reaching the photostationary state. Inset: back thermal relaxation in the dark (thick black) and biexponential fit (thin white) at the absorbance maximum 469 and $474 \mathrm{~nm}$, respectively. 
Table 2. Photophysical and photochromic properties of azoCO ${ }_{2} \mathrm{Me}$ and azoCO ${ }_{2} \mathrm{H}$ spin-coated thin films (200 $\mathrm{nm}$ thick).

\begin{tabular}{lcccccc}
\hline & $\begin{array}{c}\lambda_{\max } \\
{[\mathrm{nm}]}\end{array}$ & $\begin{array}{c}\rho \in z^{\min } \\
{[\%]^{\mathrm{a})}}\end{array}$ & $\begin{array}{c}k_{1} \\
{\left[10^{-5} \mathrm{~s}^{-1}\right]^{\mathrm{b})}}\end{array}$ & $f_{1}$ & $\begin{array}{c}k_{2} \\
{\left[10^{-5} \mathrm{~s}^{-1}\right]^{\mathrm{b})}}\end{array}$ & $f_{2}$ \\
\hline azoCO2Me & 469 & 27 & 4.7 & 95 & 35 & 4.5 \\
azoCO $_{2} \mathrm{H}$ & 474 & 19 & 5.9 & 96 & 62 & 3.8 \\
\hline
\end{tabular}

a) Minimum photoconversion yield $E \rightarrow Z$ (assuming that the $Z$ form does not absorb at $488 \mathrm{~nm})$ obtained by irradiation at $488 \mathrm{~nm}\left(7 \mathrm{~mW} \mathrm{~cm}{ }^{-2}\right)$; b) Biexponential fit $a_{1} \exp \left(-k_{1} t\right)+a_{2} \exp \left(-k_{2} t\right)$ with $k_{i}=1 / \tau_{i}$. and normalized fractions defined as $f_{i}=a_{i} k_{i} /\left(a_{i} k_{i}+a_{j} k_{j}\right)$.

E forms. Such assumption is reinforced by the amplified difference in photochromic performance for azo thin films with a much lower $\rho_{\mathrm{EZ}}{ }^{\mathrm{min}}$ value for $\mathbf{a z o C O}_{2} \mathrm{H}(19 \%)$ compared to that for $\mathbf{a z o C O}_{2} \mathrm{Me}$ (27\%) (Figure 2, Table 2).

The rate constants $k_{1}$ and $k_{2}$ of the two-exponential law, nicely fitting the azo unit thermal relaxation in thin films, were found surprisingly slightly higher for $\mathbf{a z o C O}_{2} \mathbf{H}$ thin films, recalling the photochromic relaxation in ethanol. Such an evolution and the lower $\rho_{\mathrm{EZ}}{ }^{\text {min }}$ value let suggest that intermolecular $\mathrm{H}$-bonding operate, thereby rigidifying part of the dyes and impairing their photoinduced geometry transformation.

\subsection{Photoinduced Migration Ruled by Intermolecular Interactions}

In order to assess the impact of hydrogen bonds on the photomigration ability of azo dyes, the above-processed thin films with similar thicknesses of about 200-230 nm were subjected to interferential illumination using the $488 \mathrm{~nm}$ emission wavelength of an argon ion laser (Figure S5, Supporting Information). Such a film thickness allowed for reduced adhesion effects of the azo layer with the glass substrate known to impair photomigration, ${ }^{[17]}$ and yielded absorbance around 0.5 , allowing for illumination throughout the azo thin films and not only by the upper surface. The fact that both $E$ and $Z$ isomers closely absorb $^{[34]}$ makes the photomigration more efficient since both isomers could be excited at $488 \mathrm{~nm}$, near their absorption maximum. Under structured polarized light irradiation, push-pull azo materials undergo considerable mass transport according to mechanisms that keep being debated between optical, ${ }^{[35]}$ entropy-driven elastic, ${ }^{[36]}$ or mechanical effects, ${ }^{[37]}$ to form surface relief gratings (SRGs). Progress in the SRG formation can then simply be followed by recording the firstorder diffracted intensity $I_{ \pm 1}$ of a low-power He-Ne laser beam at $633 \mathrm{~nm}(1.9 \mathrm{~mW})$ that continuously probes the illuminated area as the latter gradually transforms into a periodic structure that is measurable using AFM. SRG height and rate of writing are actually ruled by extrinsic factors like the incident light polarization and energy dose, and intrinsic properties inherent to the dyes in terms of structural orientation and organization, absorption efficiency, and photochromic response. We thus first investigated the impact of the incident light irradiance that was varied from 80 to 160 and finally $240 \mathrm{~mW} \mathrm{~cm}{ }^{-2}$ for each beam. We resorted to the configuration of $+45^{\circ} /-45^{\circ}$ polarized beams which was proven to promote efficient mass transport and polarization grating with an irradiation intensity nearly constant. ${ }^{[38]}$ Logically, the higher the intensity, the faster the $I_{ \pm 1}$ growth rate, which could be observed for both $\mathbf{a z o C O}_{2} \mathrm{H}$ and azoCO$_{2} \mathrm{Me}$ thin films (Figure 3A).

Four very interesting phenomena were observed. First, the difference in terms of growth rate tends to vanish under higher light irradiance to the benefit of $\mathbf{a z o C O}_{2} \mathrm{H}$ thin films that showed a significantly slower dynamics, almost four times less, at lower irradiance. The provided energy density $E$ remains almost constant at around $24 \mathrm{~J} \mathrm{~cm}^{-2}$ to reach the $I_{ \pm 1}$ plateau for $\mathrm{azoCO}_{2} \mathrm{Me}$ thin films whereas it diminished from 84 to $53 \mathrm{~J} \mathrm{~cm}^{-2}$ for $\operatorname{azoCO}_{2} \mathrm{H}$ when increasing the light irradiance from 80 to $240 \mathrm{~mW} \mathrm{~cm}{ }^{-2}$, suggesting impeding interactions between the $\mathbf{a z o C O}_{2} \mathrm{H}$ dyes (Table S2, Supporting Information). Indeed, quantitative DSC measurements evidenced a much lower heat capacity change $\Delta C_{\mathrm{p}}$ at glass transition $T_{\mathrm{g}}\left(\Delta C_{\mathrm{p}}=0.09\right.$ and $0.25 \pm 0.03 \mathrm{~J} \mathrm{~g}^{-1} \mathrm{~K}^{-1}$ for $\mathbf{a z o C O}_{2} \mathrm{H}$ and $\mathbf{a z o C O}_{2} \mathrm{Me}$, respectively). Low $\Delta C_{\mathrm{p}}$ values illustrate more ordered materials but also stiffer cohesion as found for tridimensional polymeric networks where $\Delta C_{\mathrm{p}}$ values decrease with increasing crosslinking density. ${ }^{[39]}$ We could thus ascribe the gain of mobility at higher irradiance for $\mathbf{a z o C O}_{2} \mathbf{H}$ to the requested amount of photon energy to disrupt the intermolecular hydrogen bonds and impart dye with larger mobility. Considering the irradiance difference between 160 and $240 \mathrm{~mW} \mathrm{~cm}{ }^{-2}$ requested to bring excess of mobility, we obtain an additional number of $\approx 3300$ photons that must be absorbed by the $\mathrm{azoCO}_{2} \mathrm{H}$ molecules with respect to $\mathrm{azoCO}_{2} \mathrm{Me}$ ones (see the Supporting Information for calculations). The second noteworthy feature relates to the SRG peak-to-trough height that was found very similar (between 130 and $155 \mathrm{~nm}$ ), whatever the compound and the incident irradiance (Figure $3 \mathrm{C}$ ). This tends to suggest similar microscopic distribution of both the ester and carboxylic acid dyes after photomigration as if any significant intermolecular bonds, and especially hydrogen ones, had been disrupted. The third interesting observation is the much thinner matter fringes systematically found for $\mathbf{a z o C O}_{2} \mathrm{H}$. Larger cohesion between the carboxylic acid functions of azo dyes could be evoked as a possible explanation of the lesser migration of the azo acids with respect to their ester analogs, as a consequence of quite rigidly hydrogenbonded photochromes. Finally, when looking more carefully at $\mathbf{a z o} \mathrm{CO}_{2} \mathrm{Me}$ gratings generated at high laser irradiance, very slight deformation of the fringes could be noticed although the diffracted $I_{ \pm 1}$ signal remained constant (Figure 3B upper right, Figure 4A).

\subsection{Modulation of the Amplitude of Micrometer-High Superstructures}

When using $90^{\circ}$ (namely, p-polarized) instead of $45^{\circ}$ polarized interfering beams, dramatic amplification of the deformation, characterized by a notable loss of the diffracted $I_{ \pm 1}$ signal, was observed after $5 \mathrm{~min}$ for $\mathbf{a z o C O}_{2} \mathbf{H}$ and $15 \mathrm{~min}$ for $\mathbf{a z o C O}_{2} \mathbf{M e}$ (Figure 4A and Figure S6, Supporting Information). The latter configuration, known as $\mathrm{p} / \mathrm{p}$ polarization configuration, generated intensity-modulated light patterns that considerably impacted the geometry of SRGs over time, evolving into very large micrometer-high patterns with respect to the initial thickness. 
A

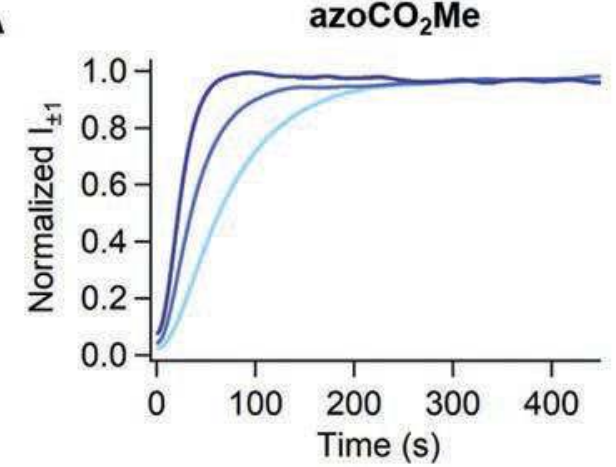

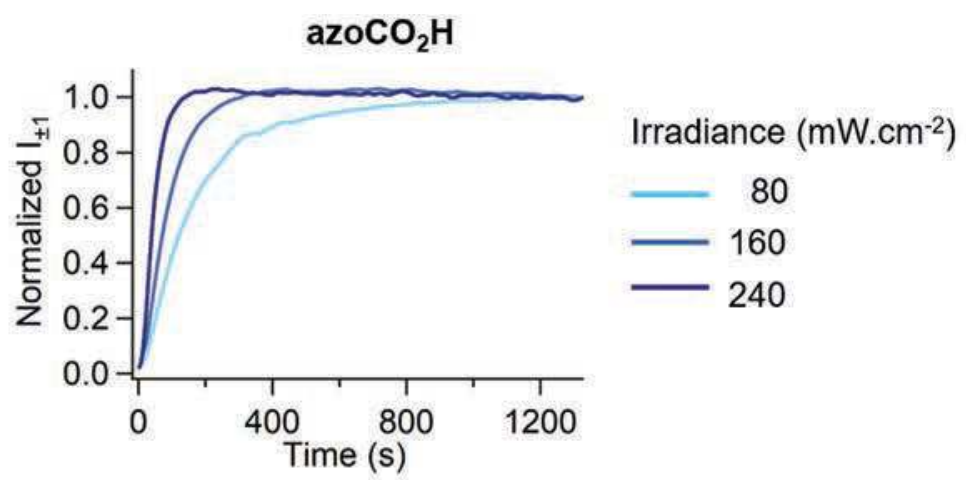
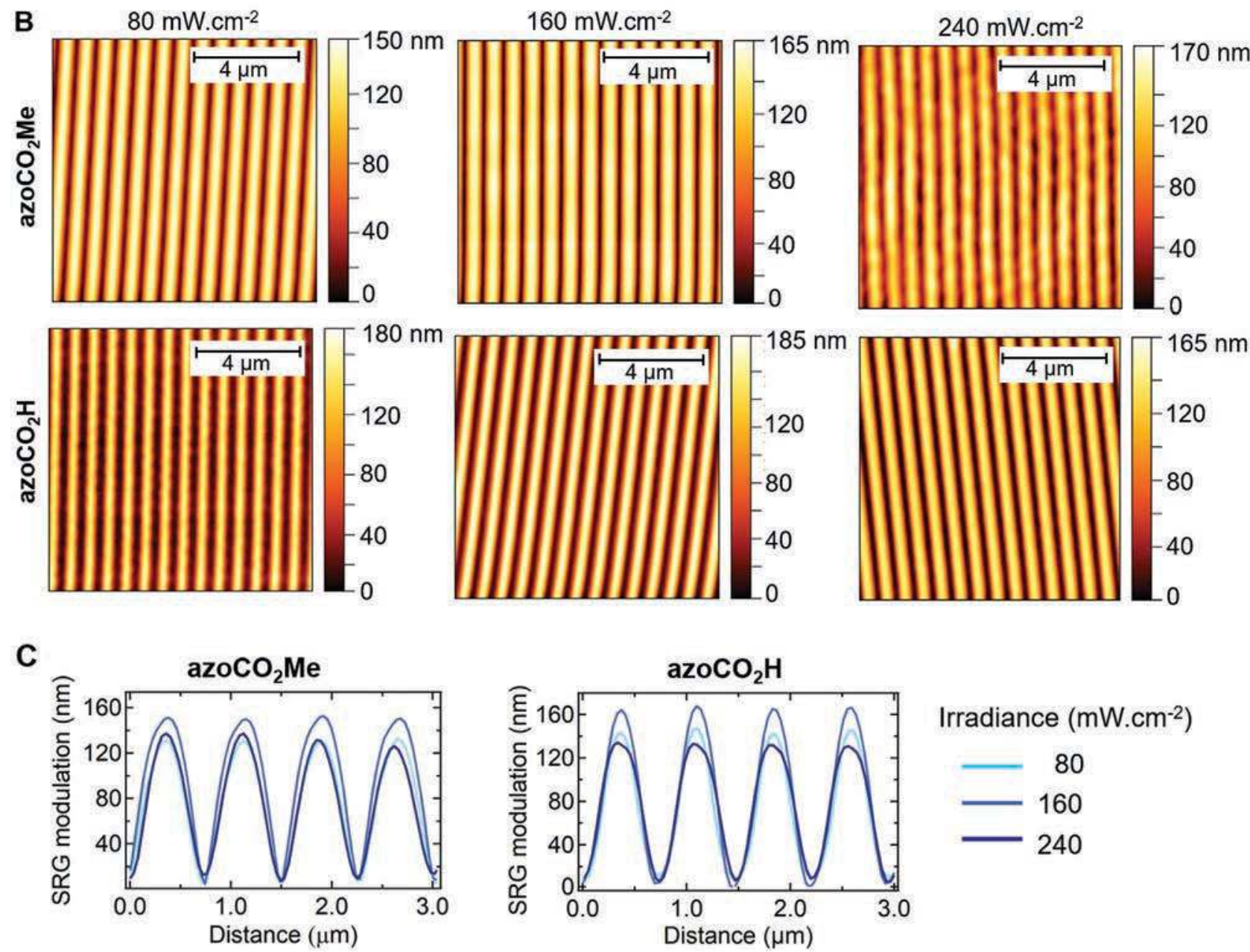

\section{Irradiance $\left(\mathrm{mW} . \mathrm{cm}^{-2}\right)$}
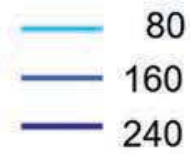

Figure 3. Interferential illumination of azoCO $\mathrm{CO}_{2} \mathrm{Me}$ and $\mathrm{azoCO}_{2} \mathrm{H}$ thin films using two $\mathrm{Ar}^{+}$laser beams at $488 \mathrm{~nm}$ with $+45^{\circ} /-45^{\circ}$ polarization $\mathrm{configu}-$ ration as a function of the incident light irradiance $\left(80,160\right.$, and $240 \mathrm{~mW} \mathrm{~cm}{ }^{-2}$ per beam). A) Time evolution of the normalized first-order diffraction intensity $I_{ \pm 1}$ of a He-Ne probe laser beam during interferential illumination. B) AFM images recorded after having reached constant $I_{ \pm 1}$ signals. C) SRG surface profiles measured by AFM after having reached constant $I_{ \pm 1}$ signals.

This conducted to worm-like patterns as high as 1.11 and $0.74 \mu \mathrm{m}$ for $\mathbf{a z o C O} \mathrm{C}_{2} \mathrm{Me}$ and $\mathbf{a z o C O} \mathrm{CO}_{2} \mathrm{H}$ thin films and separated by a few microns, roughly 2.9 and $1.8 \mu \mathrm{m}$, respectively (Figure 4B).

As previously noted, both azo derivatives again display distinct dynamics and pattern geometries, with clear advantage to $\mathbf{a z o C O} \mathbf{C O}_{2} \mathrm{Me}$ in terms of speed and relief amplitude. To gain insight in the formation of the "superstructures," topographic
AFM follow-up of the photoinduced patterns was performed after $2,8,15,30$, and $60 \mathrm{~min}$ of irradiation and evidenced neat migration of the azo dyes along the already formed vertical SRGs (Figure 5 and Figure S6 for 3D view, Supporting Information). Matter depletion progressively occurred, until collapsing into bulk motifs, orthogonally oriented relative to the direction of the initial SRGs. 

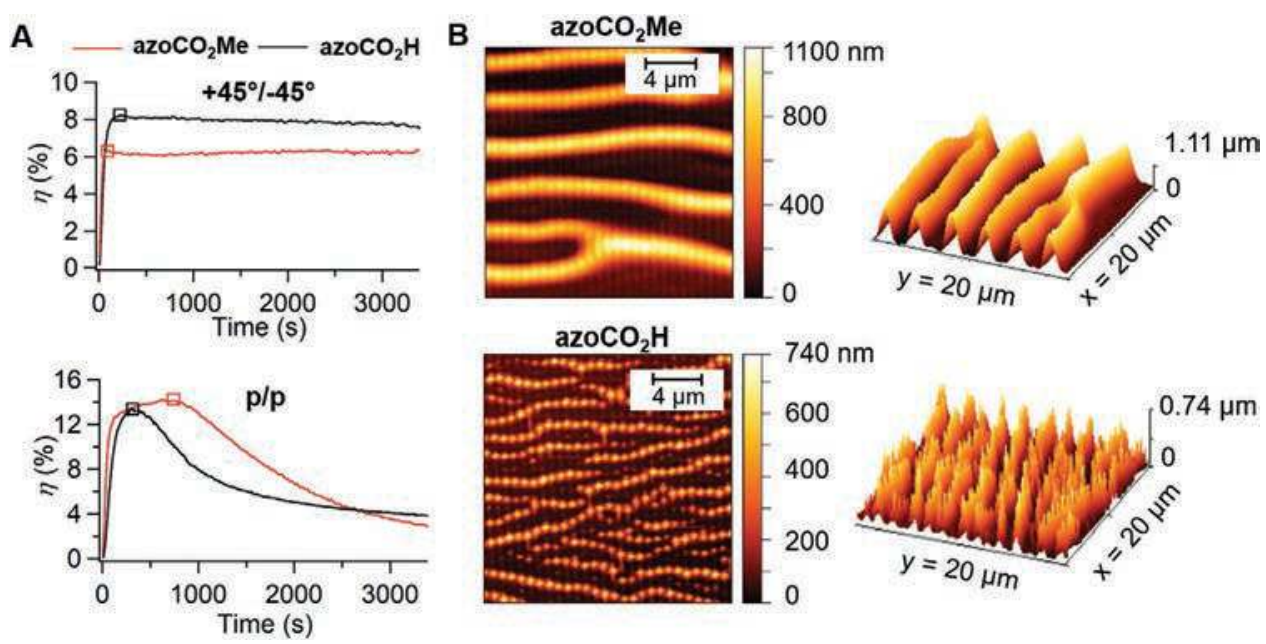

Figure 4. A) Time evolution of the first-order diffraction efficiency $\eta$ of $\mathbf{a z o C O}_{2} \mathrm{Me}$ (red curve) and azoCO $\mathrm{H}_{2} \mathrm{H}$ (black curve) thin films subjected to $+45^{\circ} /-45^{\circ}$ (top) and $\mathrm{p} / \mathrm{p}$ (bottom) interferential illumination at $488 \mathrm{~nm}\left(240 \mathrm{~mW} \mathrm{~cm}{ }^{-2}\right.$ each beam). Diffraction efficiency maxima are indicated by empty squares. B) AFM imaging (2D and $3 \mathrm{D}$ views) of $\mathrm{azoCO}_{2} \mathrm{Me}$ and $\mathrm{azoCO}{ }_{2} \mathrm{H}$ thin films after $\mathrm{p} / \mathrm{p}$ interferential illumination at $488 \mathrm{~nm}$ for $1 \mathrm{~h}$ $\left(240 \mathrm{~mW} \mathrm{~cm}{ }^{-2}\right.$ each beam).

To our surprise, the relief amplitude showed strong dependence on the interference periodic spacing $\Lambda$. The latter could be varied by changing the incidence angle $\theta$ of the two interfering beams as a consequence of the Bragg's law $\lambda=2 \Lambda \sin \theta$. Hence, light patterns with decreasing $\Lambda$ values $(1.00,0.74$, and $0.52 \mu \mathrm{m})$ induced an almost threefold increase in the superstructure amplitude reaching up to $2.13 \mu \mathrm{m}$ for the smallest interfringe spacing $\Lambda$ (Figure 6).

To our knowledge, such a remarkable surface relief amplitude with respect to the initial film thickness, reaching ten times the height of the nonilluminated film, has never been reported so far. The formation of such longitudinal micrometer-high superstructures recalls previous reports on "spontaneous" patterns mostly observed in azo polymers and more rarely in molecular azo materials, induced either by on $\mathrm{e}^{[40]}$ or two polarized laser beams. ${ }^{[25,41]}$ For most samples, large irradiance varying from $300 \mathrm{~mW} \mathrm{~cm}{ }^{-2}$ to $4 \mathrm{~W} \mathrm{~cm}^{-2}$ were usually required to achieve wrinkled surfaces with motifs significantly smaller than $1 \mu \mathrm{m}$ starting from micrometer-high samples. In our case, such superstructures only appeared under $\mathrm{p} / \mathrm{p}$ polarized impinging interferences. Indeed, $\mathrm{s} / \mathrm{s}$ interferences provided regular SRGs with a very low peak-to-trough amplitude $(20 \mathrm{~nm})$ in the same irradiation conditions (Figure S7, Supporting Information), while no particularly regular motifs and a random corrugation were obtained under illumination using one single beam (Figure S8, Supporting Information). Moreover, the structuration observed in our case occurred at a significantly lower energy than that commonly used for azo polymers, and its amplitude showed obvious dependence on the spatial period $\Lambda$ of the initial gratings This observation lets us suggest that strong intensity modulation, associated with smaller interfringe spacing, is essential to massive and unidirectional dye photomigration. Second-order interferential optical effects created by the initially formed SRGs have
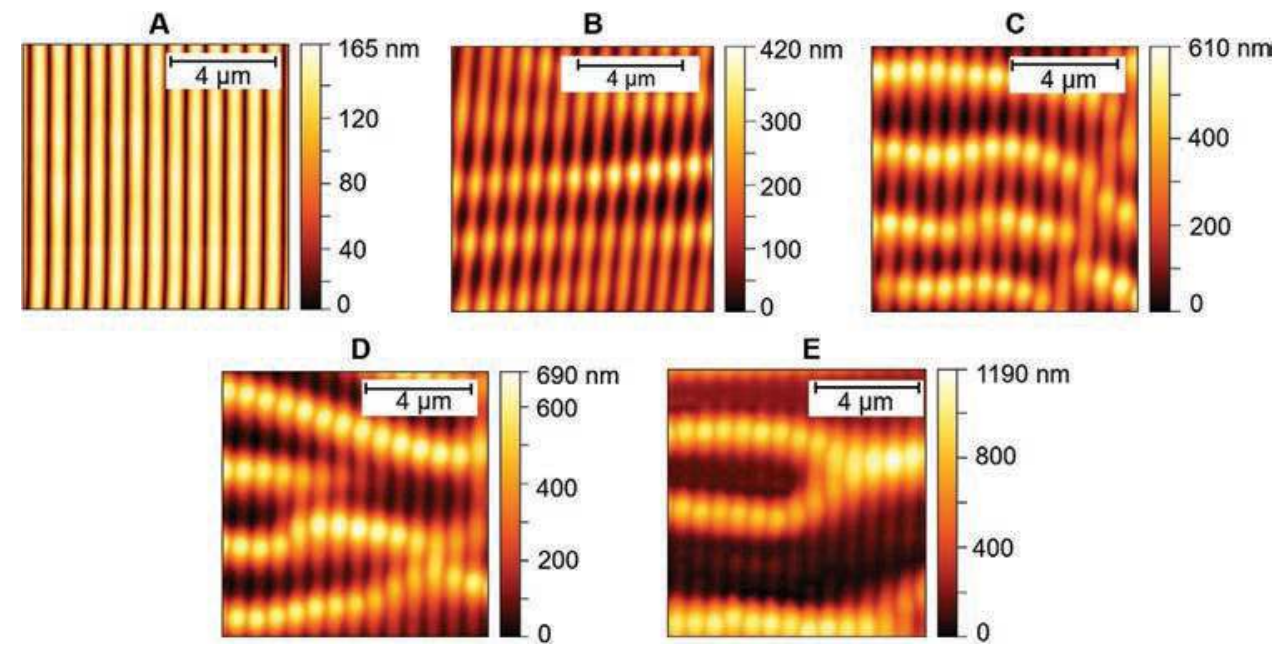

Figure 5. AFM imaging of azoCO$_{2} \mathrm{Me}$ thin film subjected to interferential illumination at $488 \mathrm{~nm}$ with a p/p polarization configuration $\left(240 \mathrm{~mW} \mathrm{~cm}^{-2}\right.$ each beam, $\Lambda=0.74 \mu \mathrm{m}$ ) after irradiation for: A) 2, B) 8 , C) 15 , D) 30 , and E) $60 \mathrm{~min}$. 

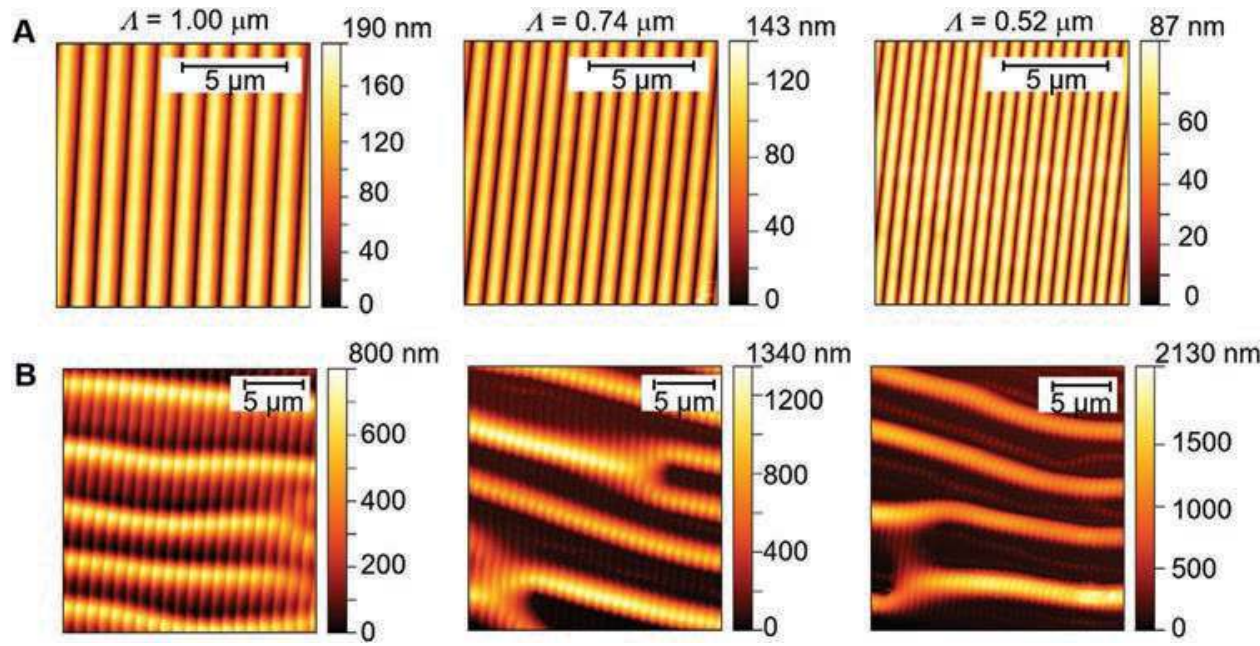

Figure 6. AFM images of $\mathrm{azoCO}_{2} \mathrm{Me}$ thin films subjected to interferential illumination at $488 \mathrm{~nm}\left(240 \mathrm{~mW} \mathrm{~cm}^{-2}\right.$ each beam) as a function of the periodic spacing of the light interferences ( 1.00 (left), 0.74 (middle), and 0.52 (right) $\mu \mathrm{m})$. A) $+45^{\circ} /-45^{\circ}$ polarization configuration ( $2 \mathrm{~min}$ irradiation). B) $\mathrm{P} / \mathrm{P}$ polarization configuration (60 min irradiation).

been proposed to be responsible for the large restructuration effects. ${ }^{[25,41 b, 42]}$ In our case, the dependence between the superstructures and initially formed SRGs can be evidenced from the fast Fourier transform (FFT) pattern calculated from the optical transmission microscopy images collected under low magnification with a $20 \times$ objective. FFT patterns for azoCO$_{2} \mathrm{Me}$ thin films revealed smaller interspacing for the superstructures issued from SRGs with smaller interfringe (e.g., features distant from 1.48 and $3.72 \mu \mathrm{m}$ for $\Lambda(\mathrm{SRG})=0.74 \mu \mathrm{m}$, and 1.72 and $4.60 \mu \mathrm{m}$ for $\Lambda(\mathrm{SRG})=1.00 \mu \mathrm{m})$ (Figure $\mathrm{S} 9$, Supporting Information). It would be tempting to evoke second-order optical effects due to the noted relationships. However, they would not explain the orthogonal mass transfer of the azo material with respect to the initial migration occurring in the first minute. For the same reasons, the assumption of backside optical reflection by the glass substrate supporting the spin-coated azo film can also be excluded as previously established. ${ }^{[40 a]}$ Segregation effects and matter instability caused by strong immiscibility between $E$ and $Z$ units were put forward to explain the rise of high structures in azo polymers under irradiation with one single polarized beam. ${ }^{[40 \mathrm{c}]}$ In the case of small molecule-based thin films, the mixing entropy between distinct molecules is known as very large, which minimizes the risk of segregation in glass-forming monomeric materials. ${ }^{[43]}$ On a microscopic point of view, strong immiscibility means significantly distinct electronic structures and intermolecular interactions between both $E$ and $\mathrm{Z}$ isomers, and their chemical surroundings. Here, it turns out that quantum chemistry calculations performed on $\operatorname{azoCO}_{2} \mathrm{Me}$ and $\operatorname{azoCO}_{2} \mathrm{H}$ returned very similar values for the computed dipole moments of the $E$ and $Z$ azo isomers in their ground state, namely, 5.8 versus $5.4 \mathrm{D}$, respectively, for azoCO${ }_{2} \mathrm{Me}$, and 6.6 versus $5.4 \mathrm{D}$, respectively, for $\mathbf{a z o C O}_{2} \mathrm{H}$ in quite polar surroundings like THF. So, given the little change in dipole moment achieved for the most mobile $\mathbf{a z o C O}_{2} \mathrm{Me}$ dye, phase separation between the $E$ and $Z$ units cannot be evoked as a possible reason of the appearance of high patterns. On the contrary, we suspect that weakly modified intermolecular interactions allowing for strong cooperativity effects, and large geometrical changes upon photoisomerization (Figure S4, Supporting Information) are precisely one of the key factors underlying very effective migration, in addition to the contributions of thermal diffusion and orientational anisotropy discussed hereafter.

\subsection{Evidence of Mechanical and Elastic Modulus Changes}

To go beyond purely optical and electronic effects, thermal and plasticization effects, due to distinct viscoelastic properties of the $E$ and $Z$ isomers have been proposed to explain SRG generation and the rise of "spontaneous" SRG-like patterns. The arguments advanced by several authors were based on elegant thermodynamic models, developed again in azo polymers and pointing out the temperature-dependent mechanical stress induced by azo dye orientation under polarized irradiation. ${ }^{[4]}$ Also, recent studies reported the influence of temperature on azo polymers $\left(T_{\mathrm{g}}=71^{\circ} \mathrm{C}\right)$ subjected to homogenous illumination for long irradiation times up to $4 \mathrm{~h}$ to help dyes diffuse in thin films. ${ }^{[45]}$ In this study, the increase in temperature from -200 to $0{ }^{\circ} \mathrm{C}$ of a photoirradiated sample placed in a cryogenic chamber was accompanied by the generation of thicker and more extended wrinkles, ascribed to azo dye thermal diffusion. In order to evidence possible heating effects due to continuous irradiation over $1 \mathrm{~h}$, which could favor the formation of superstructures upon bulk material softening, we recorded the temperature evolution of the irradiated area of an $\mathbf{a z o C O}_{2} \mathbf{M e}$ thin film that showed the most remarkable photostructuration, using a high-speed IR camera (Figure S10, Supporting Information). The temperature evolution was imaged in three locations: within the beam illumination area (spot \#1), close to $(0.22 \mathrm{~cm}$ distance; spot \#2) and far from $(0.91 \mathrm{~cm}$; spot \#3) the beam center. The temperature rapidly rose from 20.8 to $25.9^{\circ} \mathrm{C}$ over $140 \mathrm{~s}$ and then monotonously decreased to the final temperature of $24.2^{\circ} \mathrm{C}$. All three spots followed the same evolution that interestingly matched at short times the increase of the firstorder diffraction intensity. The fact that spot \#3 far from the 
illuminated area also underwent thermal heating lets suggest fast thermal thermalization, taking place after illumination. Nevertheless, given the glass transition temperature $T_{\mathrm{g}}$ of azo$\mathrm{CO}_{2} \mathrm{Me}$ determined at $110{ }^{\circ} \mathrm{C}$ and the weak difference $\Delta T=-5^{\circ} \mathrm{C}$ recorded during the whole process, direct macroscopic heating could reasonably be ruled out as the main cause of the structuration phenomena observed in our studies. Since macroscopic temperature measurements do not accurately describe the microscopic changes undergone in the material, we turned our attention to the mechanical measurements of $\mathbf{a z o C O}_{2} \mathrm{Me}$ thin films using the AFM PeakForce mode. QNM investigations, aiming at assessing the Young's modulus E, and adhesion to account for the material mechanical responses were performed on the sample displaying the larger SRG periodic spacing $(1 \mu \mathrm{m})$, on SRGs before deformation and in the area where the superstructures formed (Figure 7 and Figure S11, Supporting Information). Three remarkable features were worth noting (Figure 7A). First, the Young's modulus E changed by almost two orders of magnitude from 0.04 to $2.04 \mathrm{GPa}$ for the superstructured sample whereas it only doubled from 1.29 to $2.50 \mathrm{GPa}$ for the regular SRGs (Figure 7B). Second, The $E$ variation was found out of phase with the superstructures, namely, the lower values were found at the superstructure maxima, which contrasts with the regular SRGs displaying larger $E$ values in the crests (Figure S11B, Supporting Information). Both unexpected results already bring to the conclusion that the superstructures display a lower material density than that of the starting material as a result of a large free volume created during the secondary step of azo photomigration. Conversely, no such change occurred for the material having formed SRGs

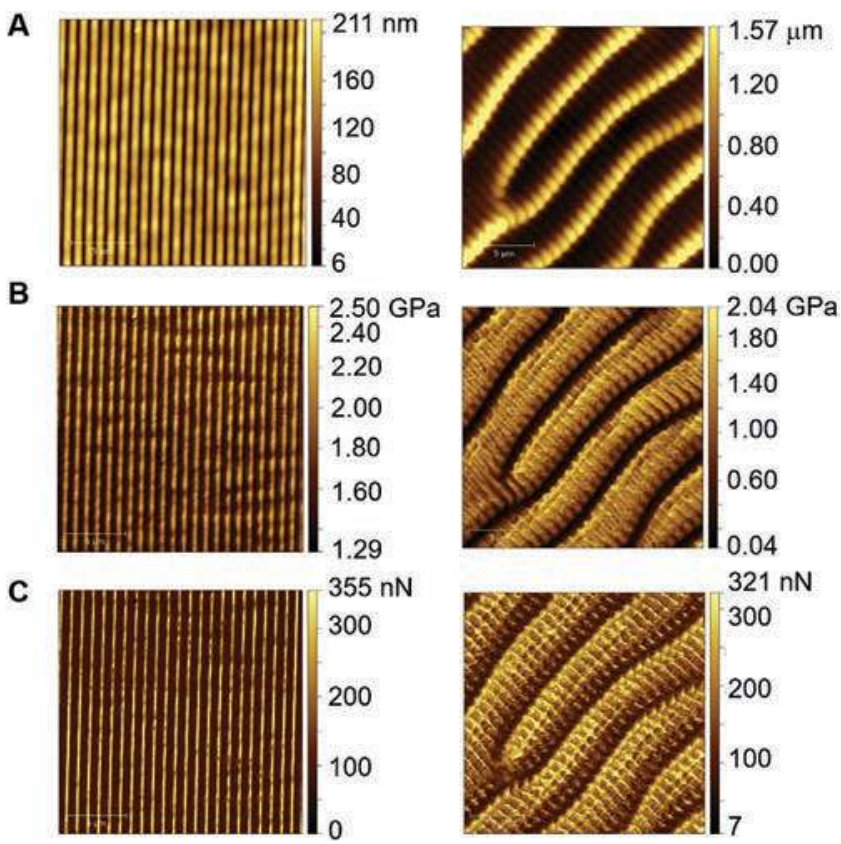

Figure 7. AFM quantitative nanomechanical measurements performed in a PeakForce QNM mode on azoCO $_{2}$ Me thin film (thickness $300 \mathrm{~nm}$ ) subjected to interferential illumination at $488 \mathrm{~nm}\left(240 \mathrm{~mW} \mathrm{~cm}{ }^{-2}\right.$ each beam, p-polarized beams, $1 \mu \mathrm{m}$ periodic spacing): A) topography; B: Young's modulus E; C) adhesion. Left views: regular SRGs before superstructuration. Right views: area of superstructures after SRG superstructuration. in the first step with regard to the initial state. Finally, the third interesting observation relates to the very similar adhesion forces characterizing the interactions between the sample and the tip during the tip withdrawal from the surface (Figure 7C). Adhesion mapping matched the sample topography but was out of phase with the superstructure Young's modulus.

All these observations clearly point out the creation of amplified free volume during the formation of the high superstructures, as a consequence of the great difference in geometry (see computed geometries in Figure S4 in the Supporting Information, leading to a molecular volume twice as large for $E\left(\approx 5900 \AA^{3}\right)$ compared to that for $Z\left(\approx 3100 \AA^{3}\right)$ rather than in electronic properties between the $E$ and $Z$ isomers, endowed with similar dipole moments. Indeed, the adhesion variation did not display strong discrepancy between both investigated locations. Hence, we assume that the observed superstructures arise from larger matter disorganization operating in a second phase, driven by "spontaneous" thermal relaxation and orientational anisotropy as proposed below, without generating particular molecular $\pi-\pi$ stacking between the azo backbone as earlier proposed in azo polymers. ${ }^{[46]}$

\subsection{Erasure and Orientational Anisotropy}

Azo derivatives have been known for long to induce strong microscopic fluidization effects in the solid state as a result of repetitive $E-Z$ isomerization cycles. This in turn can promote among others the alignment of polar dyes in an azo matrix along the direction of an external electric field, ${ }^{[47]}$ induce local reorganization of liquid crystal matrices to move microparticles, ${ }^{[48]}$ or command directional filling of etched channels by photoirradiating azo polymers with specific light polarization. ${ }^{[49]}$ As for azo-based SRGs, single-beam or nonpolarized homogenous illuminations are known to provoke efficient thin film flattening, ${ }^{[50]}$ as a consequence of iterated cycles of $E-Z$ and $Z$-E photoisomerization. The fact that both $E$ and $Z$ isomers can undergo rotational diffusion in their ground states, ${ }^{[51]}$ leads to random azo migration and disappearance of the volume gratings. Successful erasure was achieved for SRGs written with a $+45^{\circ} /-45^{\circ}$ polarization configuration, using a singlebeam illumination which consists in simply blocking one laser beam. After $10 \mathrm{~min}$, only residual $I_{ \pm 1}$ diffracted intensity could be measured, while smooth surface was imaged by AFM (Figure 8A).

Recovery of the initial $I_{ \pm 1}$ value and SRG height was achieved for both compounds by exposing the thin films to a novel interferential illumination. Writing-erasure cyclability was nicely tested for $\mathbf{a z o C O} \mathrm{CO}_{2} \mathrm{Me}$ by following the diffracted signal (Figure S12A, Supporting Information). Interestingly, a slight rise of the first-order diffraction efficiency $\eta$ and erasure kinetics could be noticed after each step as a consequence of local fluidification by the photoisomerizing azo dyes, in agreement with the above-mentioned AFM mechanical investigations. ${ }^{[52]}$ The photorewritability capacity could be exploited to easily fabricate egg-box structures by rotating by $90^{\circ}$ samples containing photowritten SRGs, and shining a $45^{\circ} /-45^{\circ}$ polarized illumination until the intensity diffracted by the first grating decreased by $50 \%$. In this way, both $\mathbf{a z o C O}{ }_{2} \mathbf{M e}$ and $\mathbf{a z o C O}_{2} \mathbf{H}$ successfully 
A
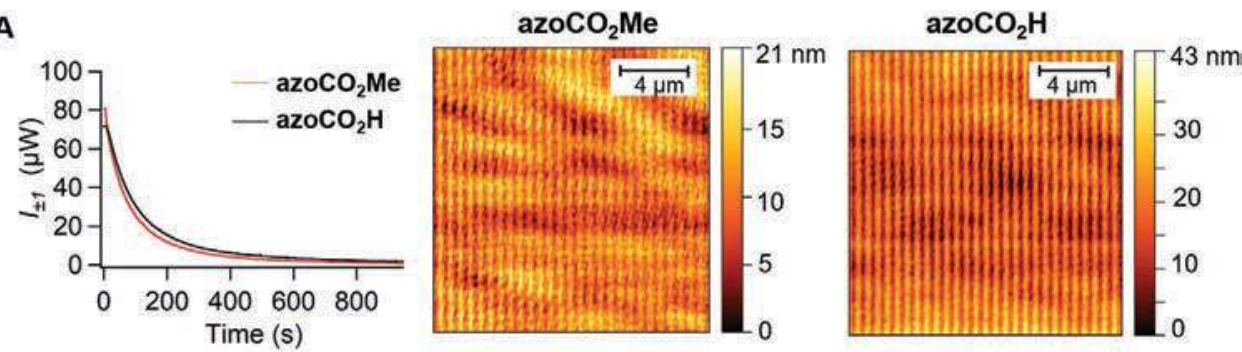

B
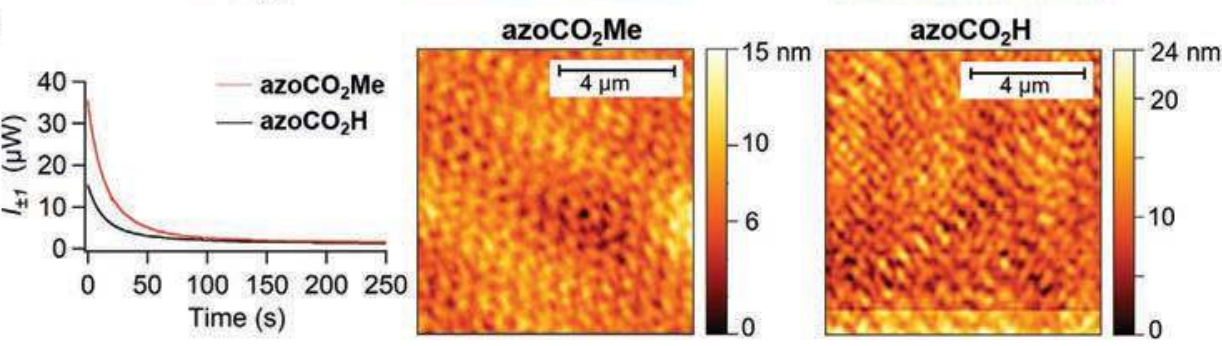

Figure 8. Time-evolution of the first-order diffracted intensity $I_{ \pm 1}$ upon SRG erasure (left) and AFM images after erasing $S R G s$ written on azoCO ${ }_{2} M e$ (middle) and $\mathbf{a z o C O}_{2} \mathrm{H}$ films (right). A) Writing step: two interfering beams with a $+45^{\circ} /-45^{\circ}$ polarization configuration (1-2 min); erasure step: single beam with $45^{\circ}$ polarization ( $\left.15 \mathrm{~min}\right)$. B) Writing step: two interfering beams with a p/p polarization configuration (60 min); erasure step: two beams with an s/s polarization configuration $(3 \mathrm{~min})\left(488 \mathrm{~nm}, 240 \mathrm{~mW} \mathrm{~cm}{ }^{-2}\right.$ for each beam).

generated egg-box structures (Figures S12B and S13, Supporting Information).

Such erasure experiments using one p-polarized beam or homogenous nonpolarized completely failed when applied to the superstructures written in $\mathbf{a z o C O}{ }_{2} \mathrm{Me}$ thin films, issued from $\mathrm{p} / \mathrm{p}$ irradiation. Conversely, orthogonally polarized illumination, involving one or two s-polarized beams, induced very fast decline of the $I_{ \pm 1}$ intensity within 20 min or less than $3 \mathrm{~min}$, respectively, while AFM imaging revealed remarkably flattened surfaces (Figure 8B). Under continuous illumination conditions, the absorption probability $P_{\text {abs }}$ by the azo compounds is actually ruled by the matrix element $\left|\vec{\mu}_{\mathrm{eg}} \cdot{\overrightarrow{E_{0}}}^{2}\right|^{2}$ that is proportional to $\left|E_{0}\right|^{2} \cos ^{2} \phi$, where $\varphi$ designates the angle between the direction of the optical electric field $\vec{E}_{0}$ and the azo transition dipole moment $\vec{\mu}_{\text {eg }}$ between the ground state (g) and the excited state (e). The fact that the superstructures could only be erased by s-polarized light, characterized by vertically oriented $\vec{E}_{0}$, indicates that the azo units were at least vertically aligned along the gratings. This photoinduced anisotropy is to be related to the unique property of push-pull azo compounds to reorient after repeated one or two-photon polarized irradiations in a direction orthogonal to the incident light polarization. ${ }^{[33]}$ The resulting photopoling effect has largely been deployed in the past to develop high-speed electromodulators ${ }^{[54]}$ and photorefractive materials, ${ }^{[5]}$ requiring strongly anisotropic materials with quadratic nonlinear optical properties.

The appearance of orientational anisotropy and the dependence of the superstructure amplitude on the incidence angle of the writing beams invite us to propose that the transformation into superstructures of the initially formed SRGs is promoted by combined light and microscopic temperatureactivated motions, namely, thermal relaxation, of the azo compounds. Both optically and thermally isomerizations seem to be governed by distinct temporal dynamics and structural effects linked to the intrinsic azo mobility, described by the random-walk model in earlier experimental and theoretical studies. ${ }^{[56]}$ Indeed, when recalling the time evolution of the first-order diffraction intensity $I_{ \pm 1}$ for $\mathbf{a z o C O}_{2} \mathrm{H}$ and $\mathbf{a z o C O}_{2} \mathrm{Me}$ thin films irradiated under $\mathrm{p} / \mathrm{p}$ polarized light (Figure 4A, bottom), two main regimes could be distinguished (Figure 9).

First, a steep $I_{ \pm 1}$ increase at earlier time was noted, corresponding to the formation of SRGs. The photokinetic rate of $I_{ \pm 1}$ signal, inferred from a simplified model based on a monoexponential law, ${ }^{[57]}$ was found to be two to three times higher for $\mathrm{azoCO}_{2} \mathrm{Me}$ dyes when compared to that for $\mathbf{a z o C O}_{2} \mathrm{H}$ ones, similarly to what was observed for a $+45^{\circ} /-45^{\circ}$ polarized illumination (Figure 4A, top). This step is mainly driven by the interference optical gradient and to a lesser extent by the azo chemical nature. The second regime relies on the sluggish rise of $I_{ \pm 1}$ signal, that was systematically observed after the first step for azoCO ${ }_{2} \mathrm{Me}$ dyes, especially under high irradiance, followed by a monotonous $I_{ \pm 1}$ decrease due to vanishing SRGs. Interestingly, the slow rise could not be distinguished for $\mathbf{a z o C O}_{2} \mathrm{H}$ thin films, and its duration shortened with higher irradiance (from 14 to 11 and finally $9 \mathrm{~min}$ at 80,160 , and $240 \mathrm{~mW} \mathrm{~cm}^{-2}$, respectively). From AFM follow-up at $240 \mathrm{~mW} \mathrm{~cm}{ }^{-2}$ (Figure 5C), the end of the "plateau" corresponded to quite well-formed superstructures that kept growing during illumination. The paradoxical rise of $I_{ \pm 1}$ intensity despite the photoinduced SRG destruction must find its origin in a phenomenon distinct from pure mass transfer, and could be ascribed to birefringence modulation, namely, to the rise of refractive index gratings. Indeed, during the first illumination step, only massive and quite cohesive photoinduced mass migration of the randomly oriented azo compounds occurred, as inferred from nanomechanical measurements. In this first step, as smartly demonstrated by previous Raman microscopy investigations on azo polymers, that are beyond the scope of the current work, subsequent reorientation of the azo main axis perpendicular to the grating vectors was found quite weak. ${ }^{[42]}$ We can thus reasonably consider that orientational anisotropy comes only into play from the second step on. The evolution of the first-order diffraction efficiency 

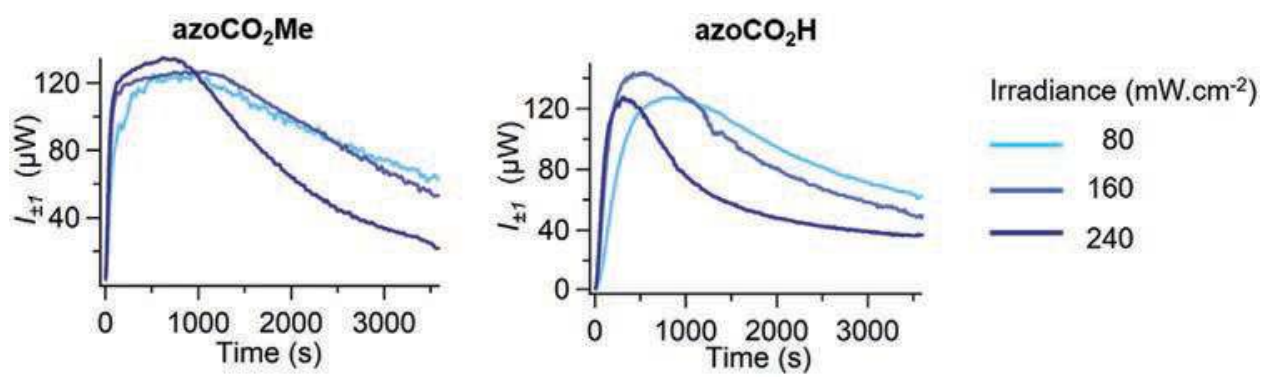

Figure 9. Time evolution of the first-order diffracted intensity $I_{ \pm 1}$ by azoCO $\mathrm{CO}_{2} \mathrm{Me}$ and $\mathrm{azoCO}_{2} \mathrm{H}$ films following interferential illumination at $488 \mathrm{~nm}$ under $\mathrm{p} / \mathrm{p}$ polarization at varying incident light irradiance $\left(80,160\right.$, and $240 \mathrm{~mW} \mathrm{~cm} \mathrm{~cm}^{-2}$ per beam, $\left.\Lambda=0.74 \mu \mathrm{m}\right)$. The rate constants of the first step increase, modeled by a monoexponential law, were found equal to $1.3 \times 10^{-2}, 2.2 \times 10^{-2}$, and $2.9 \times 10^{-2} \mathrm{~s}^{-1}$ for azoCO $\mathrm{Me}$ and $0.5 \times 10^{-2}, 0.9 \times 10^{-2}$, and $1.3 \times 10^{-2} \mathrm{~s}^{-1}$ for azoCO ${ }_{2} \mathrm{H}$ at 80,160 , and $240 \mathrm{~mW} \mathrm{~cm}{ }^{-2}$, respectively.

$\eta(t)$ actually recalls previous simulations aiming at anticipating the temporal evolution of $\eta(t)$ for azo polymers that generate bulk refractive index grating $\Delta n(t)$ and surface relief grating $\Delta \varphi(t)$ under polarized illumination. ${ }^{[58]}$ In this study, the authors considered first the major contribution of $\Delta n(t)$ and only in a second step that of $\Delta \varphi(t)$ since azo polymers yield slower SRG growth than birefringence. ${ }^{[59]}$ Provided that $\Delta n(t)$ and $\Delta \varphi(t)$ are just reversed in the case of molecular azo materials endowed with much faster migration ability compared to that of azo polymer, the reported simulations look remarkably akin to what we obtained experimentally (Figure 9). They even reproduce the distinct evolution recorded for azoCO $\mathrm{C}_{2} \mathrm{Me}$ and $\mathrm{azoCO}_{2} \mathrm{H}$, and would suggest not only larger $\Delta n$ amplitude for $\mathbf{a z o C O}_{2} \mathbf{M e}$ but also distinct phase shift between the bulk refractive index grating and surface relief grating, namely, $\pi / 2$ for $\operatorname{azoCO}_{2} \mathbf{M e}$ and $\pi$ for azoCO$_{2} \mathrm{H}$. With all these comparisons in hands and the fact that the superstructures are higher for smaller interfringes, we can envision the tentative microscopic description interpret the distinct behaviors between both azoCO$_{2} \mathrm{Me}$ and azoCO ${ }_{2} \mathbf{H}$. We need first to recall that bulk migration of azo polymers and azo molecular glasses leads to $\pi$-phase shifted SRGs with respect to the light intensity pattern, meaning that matter accumulates in null light intensity areas. ${ }^{[60]}$ After SRG formation, we propose that the azo compounds, mainly in their more compact $Z$ geometry enabling easier diffusion, start thermally relaxing in the nonilluminated peaks, which brings some of them either orthogonal to the initial polarization (Path A) or back to the bright polarized fringes which will reject them to the dark fringes with increasing orientational anisotropy after photopolymerization (Path B). Such bouncing motions of the azo dyes between bright and dark areas would stop when all azo compounds are oriented in a direction orthogonal to the electric field (in and out of the incidence plane), and the limits of molecular cooperativity are reached (Figure 10).

The model of "zig-zag" displacement along the gratings herein proposed would agree with the higher structuration observed for the SRGs with smaller interfringe spacing and amplitude. In the latter case, larger matter reorganization would be permitted by the shorter distance travelled by azo compounds from the dark to the bright areas, and vice versa. This regime and the final state highly depend on the azo structure as the height of the superstructures and the distance between two rows were systematically measured inferior for $\mathbf{a z o C O}_{2} \mathrm{H}$ thin films. We ascribe this large discrepancy to restricted rotational motions of the individual acidic chromophores due to strong ensemble interactions as abovementioned in the photochromic, spectroscopic, and thermal investigations. This observation echoes previous near-field optical studies, monitoring in situ the kinetics of surface relief formations under polarization patterns and intensity patterns. ${ }^{[61]}$ Interestingly, strong dependence

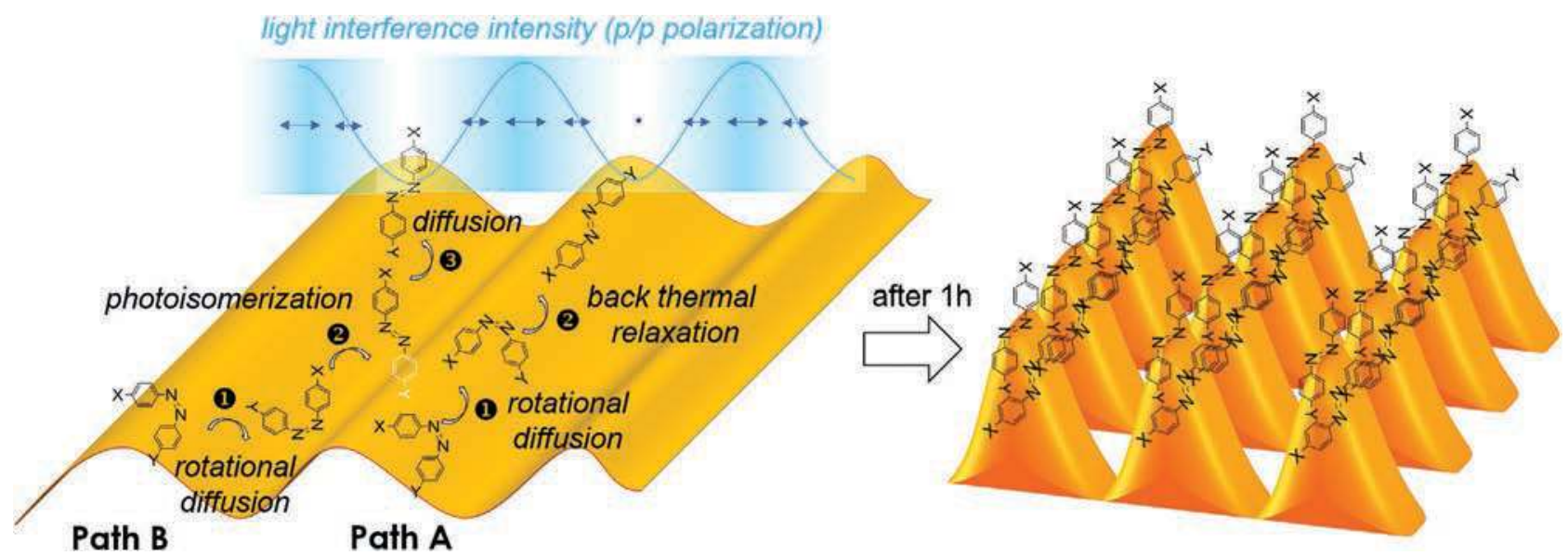

Figure 10. Schematic description of the envisioned thermal diffusion and back thermal relaxation leading to the rise of superstructures after long-time $\mathrm{p} / \mathrm{p}$ polarized illumination. 
of the chemical nature of the azo material (azo functionalized polymer vs silica sol-gels) was only noticed in the case of light intensity patterns. Competing polarization and intensitydriven mass transports were proposed to analyze the differentiated responses. In contrast to crosslinked sol-gels displaying stiff cohesion, azo-functionalized linear polymers exhibit efficient migration thanks to the large free volume around their side-chain chromophores, which led to efficient spatial migration and reorientation. Since $\mathbf{a z o C O} \mathbf{C O}_{2} \mathrm{Me}$ generates superstructures with a much higher magnitude that those issued from azoCO ${ }_{2} \mathrm{H}$ photomigration, we can reasonably conclude that large intrinsic molecular mobility, enabling extensive rotational diffusion and reorientation, appears to be a high prerequisite to any subsequent SRG evolution.

\section{Conclusion}

Two azo compounds forming small molecule-based glassy materials and differing by their ability to establish hydrogen bonds have been synthesized and their photochemical properties are investigated through a solution to solid-state continuum to evidence neat discrepancy in terms of photoreaction and photomigration under interferential illumination. Contrary to supramolecular architectures involving mostly azo-functionalized polymers, the introduction of strong H-bonding units like carboxylic acids partly hampered photoisomerization in nondoped thin films, leading to slower migration dynamics to form SRGs under light interferences. Very interestingly, identical mass transport dynamics between azo compounds devoid or endowed with hydrogen bonding units were achieved at higher illumination, indicating that light can efficiently compete with multiple noncovalent interactions evidenced by quantitative analyses. Micrometer-high structures, displaying a tenfold larger amplitude compared to the initial film thickness, arose after SRG formation when replacing polarization patterns with intensity patterns. Comparative studies of the photostructuration dynamics as a function of the incident irradiance of the interfering beams, the periodic spacing of the light interferences and eventually the azo chemical nature, let us suggest that the unexpected high reliefs result from an additional mass transfer mechanism along the gratings, inducing large matter disorganization and enhanced free volume illustrated by a twoorder decrease of the elastic modulus. We propose a "zig-zag" motion of the azo compounds, based on repeated thermally and optically activated isomerization between the areas of low and high intensity of the light patterns. Anisotropic reorientation of the azo units seems to operate, causing ultimate alignment of their main axis and related transition dipole moment in a direction orthogonal to the electric field of the optical interferences. Large SRG transformation observed in molecular materials appears to be highly favored by weakly interacting azo derivatives. In this way, large "free mean orientational path" is allowed along the SRGs, and would benefit from a domino-like matter reorganization where the motions of molecules at one location would be easily followed by the motions of vicinal molecules exploiting the liberated free volume. To our knowledge, this is the first time that systematic studies involving azo molecular materials, amenable to extensive photoinduced mass transport, evidence the occurrence of orientational reorganization and emphasize the need for high molecular mobility to apprehend the photoinduced evolution of SRGs written using an intensity pattern and the loss of material density. Second harmonic generation microscopy of the structured thin films is currently investigated to decipher the created local anisotropy and go a step further in the description of the microscopic factors ruling the migration mechanisms. Overall, the results reported in the present manuscript should bring strong rationale for the design of novel azo compounds to create stable polarized patterns that are highly desirable in holography and more generally in lightshaping photonic devices.

\section{Supporting Information}

Supporting Information is available from the Wiley Online Library or from the author.

\section{Acknowledgements}

The Agency for Defense Innovation (AID) of the French Ministry of Armed Forces and the Région des Pays de la Loire (France) are strongly acknowledged for their precious support regarding the Ph.D. funding of F.R. (NAP2 project no. 2018422). Arthur Lepoivre is warmly acknowledged for his great help in operating the analysis software of the IR camera. F.L.-L. and J.J. acknowledge the Natural Sciences and Engineering Research Council (NSERC) of Canada through grant RGPIN-2020-06676. S Cuénot (IMN, University of Nantes), expert in AFM nanomechanical measurements, is warmly acknowledged for the rich discussion and advices on the measurement interpretation.

\section{Conflict of Interest}

The authors declare no conflict of interest.

\section{Data Availability Statement}

The data that supports the findings of this study are available in the supplementary material of this article.

\section{Keywords}

azo photochromic materials, $\mathrm{H}$-bonding, holography, photoinduced superstructures, thermal analyses

[1] a) J. Boelke, S. Hecht, Adv. Opt. Mater. 2019, 7, 1900404; b) A. Priimagi, A. Shevchenko, J. Polym. Sci., Part B: Polym. Phys. 2014, 3, 163; c) W. Szymański, J. M. Beierle, H. A. V. Kistemaker, W. A. Velema, B. L. Feringa, Chem. Rev. 2013, 113, 6114; d) D. Dattler, G. Fuks, J. Heiser, E. Moulin, A. Perrot, X. Y. Yao, N. Giuseppone, Chem. Rev. 2020, 120, 310. 
[2] Z. Mahimwalla, K. G. Yager, J. Mamiya, A. Shishido, A. Priimagi, C. J. Barrett, Polym. Bull. 2012, 69, 967.

[3] T. Ikeda, J.-i. Mamiya, Y. Yu, Angew. Chem., Int. Ed. 2007, 46, 506.

[4] D. Stewart, C. T. Imrie, Macromolecules 1997, 30, 877.

[5] a) Y. Yu, M. Nakano, T. Ikeda, Nature 2003, 425, 145; b) A. Natansohn, P. Rochon, Chem. Rev. 2002, 102, 4139; c) T. Seki, J. Mater. Chem. C 2016, 4, 7895.

[6] K. Kumar, C. Knie, D. Bleger, M. A. Peletier, H. Friedrich, S. Hecht, D. J. Broer, M. G. Debije, A. Schenning, Nat. Commun. 2016, 7, 11975.

[7] A. S. Lubbe, W. Szymanski, B. L. Feringa, Chem. Soc. Rev. 2017, 46, 1052.

[8] L. M. Goldenberg, V. Lisinetskii, Y. Gritsai, J. Stumpe, S. Schrader, Adv. Mater. 2012, 24, 3339.

[9] V. Y. Chang, C. Fedele, A. Priimagi, A. Shishido, C. J. Barrett, Adv. Opt. Mater. 2019, 7, 1900091.

[10] a) T. Tanino, S. Yoshikawa, T. Ujike, D. Nagahama, K. Moriwaki, T. Takahashi, Y. Kotani, H. Nakano, Y. Shirota, J. Mater. Chem. 2007, 17, 4953; b) E. Ishow, B. Lebon, Y. N. He, X. G. Wang, L. Bouteiller, L. Galmiche, K. Nakatani, Chem. Mater. 2006, 18, 1261.

[11] C. Fasting, C. A. Schalley, M. Weber, O. Seitz, S. Hecht, B. Koksch, J. Dernedde, C. Graf, E. W. Knapp, R. Haag, Angew. Chem., Int. Ed. 2012, 51, 10472.

[12] Y. Zakrevskyy, J. Stumpe, C. F. J. Faul, Adv. Mater. 2006, 18, 2133.

[13] a) E. Schab-Balcerzak, H. Flakus, A. Jarczyk-Jedryka, J. Konieczkowska, M. Siwy, K. Bijak, A. Sobolewska, J. Stumpe, Opt. Mater. 2015, 47, 501; b) M. Poutanen, O. Ikkala, A. Priimagi, Macromolecules 2016, 49, 4095 .

[14] A. Priimagi, G. Cavallo, A. Forni, M. Gorynsztejn-Leben, M. Kaivola, P. Metrangolo, R. Milani, A. Shishido, T. Pilati, G. Resnati, G. Terraneo, Adv. Funct. Mater. 2012, 22, 2572.

[15] a) D. Y. Kim, L. Li, X. L. Jiang, V. Shivshankar, J. Kumar, S. K. Tripathy, Macromolecules 1995, 28, 8835; b) C. J. Barrett, P. L. Rochon, A. L. Natansohn, Appl. Phys. Lett. 1995, 66, 136; c) S. L. Oscurato, M. Salvatore, P. Maddalena, A. Ambrosio, Nanophotonics 2018, 7, 1387.

[16] C. J. Barrett, A. L. Natansohn, P. L. Rochon, J. Phys. Chem. 1996, $100,8836$.

[17] A. Jacquart, E. Morin, F. Yang, B. Geffroy, E. Ishow, Dyes Pigm. 2012, 92, 790.

[18] Y. Wang, C. Wang, X. Wang, Y. Guo, B. Xie, Z. Cui, L. Liu, L. Xu, D. Zhang, B. Yang, Chem. Mater. 2005, 17, 1265.

[19] P. Girard, J. Hemez, V. Silvestre, C. Labrugere, L. Lartigue, J. L. Duvail, E. Ishow, ChemPhotoChem 2017, 1, 6 .

[20] J. V. Ros-Lis, R. Martinez-Manez, M. Sancenon, J. Soto, K. Rurack, H. Weisshoff, Eur. J. Org. Chem. 2007, 2007, 2449.

[21] A. M. Rice, C. R. Martin, V. A. Galitskiy, A. A. Berseneva, G. A. Leith, N. B. Shustova, Chem. Rev. 2020, 120, 8790.

[22] E. Ishow, A. Brosseau, G. Clavier, K. Nakatani, R. B. Pansu, J. J. Vachon, P. Tauc, D. Chauvat, C. R. Mendonca, E. Piovesan, J. Am. Chem. Soc. 2007, 129, 8970.

[23] B. Priewisch, K. Rüch-Braun, J. Org. Chem. 2005, 70, 2350.

[24] A. Jacquart, P. Tauc, K. Nakatani, E. Ishow, J. Mater. Chem. 2009, 19, 8999.

[25] E. Ishow, R. Camacho-Aguilera, J. Guerin, A. Brosseau, K. Nakatani, Adv. Funct. Mater. 2009, 19, 796.

[26] M. Caricato, B. Mennucci, J. Tomasi, F. Ingrosso, R. Cammi, S. Corni, G. Scalmani, J. Chem. Phys. 2006, 124, 124520.

[27] A. D. Laurent, D. Jacquemin, Int. J. Quantum Chem. 2013, 113, 2019.

[28] M. J. Frisch, G. W. Trucks, H. B. Schlegel, G. E. Scuseria, M. A. Robb, J. R. Cheeseman, G. Scalmani, V. Barone, G. A. Petersson, H. Nakatsuji, X. Li, M. Caricato, A. V. Marenich, J. Bloino, B. G. Janesko, R. Gomperts, B. Mennucci, H. P. Hratchian, J. V. Ortiz, A. F. Izmaylov, J. L. Sonnenberg, D. Williams-Young,
F. Ding, F. Lipparini, F. Egidi, J. Goings, B. Peng, A. Petrone, T. Henderson, D. Ranasinghe, et al., Gaussian 16, Revision 01, Gaussian, Inc., Wallingford, CT 2016.

[29] E. Ishow, A. Brosseau, G. Clavier, K. Nakatani, P. Tauc, C. Fiorini-Debuisschert, S. Neveu, O. Sandre, A. Leaustic, Chem. Mater. 2008, 20, 6597.

[30] A. Plante, D. Mauran, S. P. Carvalho, J. Y. S. D. Pagé, C. Pellerin, O. Lebel, J. Phys. Chem. B 2009, 113, 14884.

[31] A. Faucon, J. Fresnais, A. Brosseau, P. Hulin, S. Nedellec, J. Hemez, E. Ishow, J. Mater. Chem. C 2013, 1, 3879.

[32] M. Poprawa-Smoluch, J. Baggerman, H. Zhang, H. P. A. Maas, L. De Cola, A. M. Brouwer, J. Phys. Chem. A 2006, 110, 11926.

[33] H. Rau, in Photochromism, Molecules and Systems (Eds: H. Dürr, H. Bouas-Laurent), Elsevier, Amsterdam 2003, pp. 165-188.

[34] A. Jacquart, R. M. Williams, A. M. Brouwer, E. Ishow, Chem. - Eur. J. 2012, 18, 3706.

[35] Z. Sekkat, Appl. Opt. 2016, 55, 259.

[36] M. Saphiannikova, D. Neher, J. Phys. Chem. B 2005, 109, 19428.

[37] K. G. Yager, C. J. Barrett, Macromolecules 2006, 39, 9320.

[38] H. Nakano, T. Takanashi, T. Kadota, Y. Shirota, Adv. Mater. 2002, 14, 1157.

[39] S. Araujo, F. Batteux, L. B. W. Li, N. Delpouve, A. Esposito, L. Tan, J. M. Saiter, M. Negahban, J. Polym. Sci., Part B: Polym. Phys. 2018, $56,1393$.

[40] a) C. Hubert, C. Fiorini-Debuisschert, L. Rocha, P. Raimond, J.-M. Nunzi, J. Opt. Soc. Am. B 2007, 24, 1839; b) L. Mazaheri, R. G. Sabat, O. Lebel, J. M. Nunzi, Opt. Mater. 2016, 62, 378; c) H. Galinski, A. Ambrosio, P. Maddalena, I. Schenker, R. Spolenak, F. Capasso, Proc. Natl. Acad. Sci. U. S. A. 2014, 111, 17017; d) A. Sobolewska, S. Bartkiewicz, J. Mater. Chem. C 2015, 3, 5616; e) D. A. B. Therien, N. M. Culum, D. M. McRae, L. Mazaheri, F. Lagugné-Labarthet, Opt. Mater. 2021, 112, 110775.

[41] a) S. Lee, Y. C. Jeong, J. K. Park, Appl. Phys. Lett. 2008, 93, 031912; b) F. Ciuchi, A. Mazzulla, G. Carbone, G. Cipparrone, Macromolecules 2003, 36, 5689.

[42] F. Lagugné-Labarthet, J.-L. Brunel, T. Buffeteau, C. Sourisseau, M. R. Huber, S. J. Zilker, T. Bieringer, Phys. Chem. Chem. Phys. 2000, 2, 5154.

[43] K. Naito, A. Miura, J. Phys. Chem. 1993, 97, 6240.

[44] V. Toshchevikov, M. Saphiannikova, G. Heinrich, J. Phys. Chem. B 2009, 113, 5032.

[45] V. Teboul, R. Barille, P. Tajalli, S. Ahmadi-Kandjani, H. Tajalli, S. Zielinska, E. Ortyl, Soft Matter 2015, 11, 6444.

[46] M. G. Capeluto, R. Falcione, R. F. Salvador, A. Eceiza, S. Goyanes, S. A. Ledesma, Opt. Mater. 2019, 90, 281.

[47] E. Ishow, Q. Ling, J. A. Delaire, K. Nakatani, J. Opt. A: Pure Appl. Opt. 2002, 4, S197.

[48] a) A. Kausar, H. Nagano, T. Ogata, T. Nonaka, S. Kurihara, Angew. Chem., Int. Ed. 2009, 48, 2144; b) Y. Kuwahara, T. Oda, S. Kim, T. Ogata, S. Kurihara, Mater. Lett. 2016, 181, 257.

[49] K. Kumar, C. Knie, D. Bléger, M. A. Peletier, H. Friedrich, S. Hecht, D. J. Broer, M. G. Debije, A. P. H. J. Schenning, Nat. Commun. 2016, 7, 11975.

[50] X. L. Jiang, L. Li, J. Kumar, D. Y. Kim, S. K. Tripathy, Appl. Phys. Lett. 1998, 72, 2502.

[51] M. Fischer, A. El Osman, P.-A. Blanche, M. Dumont, Synth. Met. 2000, 115, 139.

[52] J. A. Delaire, K. Nakatani, Chem. Rev. 2000, 100, 1817.

[53] a) M. Dumont, A. El Osman, Chem. Phys. 1999, 245, 437; b) S. Brasselet, J. Zyss, J. Opt. Soc. Am. B 1998, 15, 257; c) C. Fiorini, F. Charra, J. M. Nunzi, P. Raimond, J. Opt. Soc. Am. B 1997, 14, 1984.

[54] A. Apostoluk, D. Chapron, G. Gadret, B. Sahraoui, J. M. Nunzi, C. Fiorini-Debuisschert, P. Raimond, Opt. Lett. 2002, 27, 2028. 
[55] a) K. Meerholz, B. L. Volodin, B. K. Sandalphon, N. Peyghambarian, Nature 1994, 371, 497; b) B. K. Sandalphon, N. Peyghambarian, S. R. Lyon, A. B. Padias, H. K. Hall, Opt. Lett. 1994, 19, 68.

[56] a) C. Fiorini, N. Prudhomme, G. de Veyrac, I. Maurin, P. Raimond, Synth. Met. 2000, 115, 121; b) M. L. Juan, J. Plain, R. Bachelot, P. Royer, S. K. Gray, G. P. Wiederrecht, ACS Nano 2009, 3, 1573.

[57] N. Reinke, A. Draude, T. Fuhrmann, H. Franke, R. A. Lessard, Appl. Phys. B 2004, 78, 205.

[58] A. Sobolewska, A. Miniewicz, J. Phys. Chem. B 2007, 111, 1536.
[59] O. N. Oliveira, Jr., L. Li, J. Kumar, S. K. Tripathy, in Photoreactive Organic Thin Films (Eds: Z. Sekkat, W. Knoll), Academic Press, San Diego 2002, p. 57.

[60] a) F. Fabbri, Y. Lassailly, K. Lahlil, J. P. Boilot, J. Peretti, Appl. Phys. Lett. 2010, 96, 081908; b) N. C. R. Holme, L. Nikolova, S. Hvilsted, P. H. Rasmussen, R. H. Berg, P. S. Ramanujam, Appl. Phys. Lett. 1999, 74, 519; c) N. S. Yadavalli, M. Saphiannikova, S. Santer, Appl. Phys. Lett. 2014, 105, 051601.

[61] F. Fabbri, Y. Lassailly, S. Monaco, K. Lahlil, J. P. Boilot, J. Peretti, Phys. Rev. B 2012, 86, 115441. 